\title{
Investigation of model parameters for high-resolution wind energy forecasting: case studies over simple and complex terrain
}

\author{
Nikola Marjanovic ${ }^{\mathrm{a}, \mathrm{b}, *}$, Sonia Wharton ${ }^{\mathrm{b}}$, Fotini K. Chow ${ }^{\mathrm{a}}$ \\ ${ }^{a}$ University of California, Berkeley, Department of Civil and Environmental \\ Engineering, MC 1710, Berkeley, CA, 94720-1710, USA \\ ${ }^{b}$ Atmospheric, Earth and Energy Division, Lawrence Livermore National Laboratory, PO \\ Box 808, L-103, Livermore, CA, 94551, USA
}

\begin{abstract}
Wind power forecasting, turbine micrositing, and turbine design require highresolution simulations of atmospheric flow. Case studies at two West Coast North American wind farms, one with simple and one with complex terrain, are explored using the Weather Research and Forecasting (WRF) model. Both synoptically and locally-driven events that include some ramping are considered. The performance of the model with different grid nesting configurations, turbulence closures, and grid resolutions is investigated through comparisons to observation data. For the simple terrain site, no significant improvement in the simulation results is found when using higher resolution. In contrast, for the complex terrain site, there is significant improvement when using higher resolution, but only during the locally-driven event. This suggests the possibility that computational resources could be spared under
\end{abstract}

\footnotetext{
*Corresponding author at: University of California, Berkeley, Department of Civil and Environmental Engineering, MC 1710, Berkeley, CA, 94720-1710, USA

Email address: nikola_marjanovic@berkeley.edu (Nikola Marjanovic)
}

Preprint submitted to Journal of Wind Engineering and Industrial Aerodynamics August 8, 2014

(C) 2014. This manuscript version is made available under the Elsevier user license http://www.elsevier.com/open-access/userlicense/1.0/ 
certain conditions, for example when the topography is adequately resolved at coarser resolutions. Physical parameters such as soil moisture have a very large effect, but mostly for the locally-forced events for both simple and complex terrain. The effect of the PBL scheme choice varies significantly depending on the meteorological forcing and terrain. On average, prognostic TKE equation schemes perform better than non-local eddy viscosity schemes. Keywords: high-resolution simulations, terrain complexity, ramping event, wind energy forecasts

\section{1. Introduction}

2 Wind power forecasting benefits greatly from accurate predictions of at3 mospheric conditions at the heights spanned by wind turbines $\left({ }^{\sim} 40-120 \mathrm{~m}\right)$.

4 Better simulation of the relevant physics could enable operational prac5 tices such as integration of larger fractions of wind power into power grids, 6 scheduling maintenance on wind energy facilities, and defining design criteria for next-generation turbines and siting. Increases in available computational power have made high-resolution simulations of the atmospheric boundary layer more practical. The model operator, however, is required to make proper choices regarding model grid spacing, turbulence parameterization, land-surface representations and the configuration of initial and lateral boundary conditions for accurate simulations. The "proper" choice of these parameters is highly dependent on the situation under consideration.

As renewable energy sources begin to represent a larger fraction of the energy portfolio, additional strain is placed on the energy industry as these sources have to date been less predictable than traditional energy sources 
(Mahoney et al., 2012). Precise spatial analysis of weather events and improved weather prediction are crucial to both long and short-term energy management. Accurate short-term (minutes to days) forecasting increases the amount of wind power which can be integrated into electrical grid operations at a lower cost as it allows operators to make better real-time and dayahead operations decisions. These decisions lead to a more efficient energy market by reducing the amount of polluting energy reserves (e.g., natural gas, coal) needed to maintain system security (Marquis et al., 2011).

This paper analyzes and investigates some of the available parameters for atmospheric modeling for wind energy applications and their effects on predictions of wind speed at turbine hub heights for two case studies. We investigate several time periods which include ramping events at two wind farm locations on the West Coast of the United States, one over simple and the other over more complex terrain. "Ramping" refers to a rapid change in wind speed over a short time period and is of great interest to wind farm operators for preventing turbine fatigue and predicting power output. The exact definition of a ramping event varies in practice; examples include a $20 \%$ capacity change in production over a thirty-minute period (Freedman et al., 2008), or a pre-specified change in the magnitude of system-wide production. In this paper, a ramping event is defined as an increase or decrease in wind speed of at least $7 \mathrm{~m} / \mathrm{s}$ in less than 3 hours.

Atmospheric conditions have a large effect on the predictability of wind speed and ramping events. Meteorologically-driven wind and ramping events may be due to atmospheric motions at several scales. For example, thermallydriven winds such as sea breezes, mountain-valley circulations, or low-level 
jets occur at local scales, whereas the passage of a cold front is a synopticallydriven phenomenon. In all these cases, associated wind transitions may simply appear as large ramps in the wind speed time series to wind farm systems operators, though the cause for the wind changes can be quite different (Freedman et al., 2008). Larger, synoptically-driven features have longer time scales and are expected in theory to be more straightforward to forecast than local-scale phenomena, which usually require fine scale information about land-surface conditions and turbulent mixing in the atmosphere.

In addition to the synoptic conditions, local topography can significantly affect a model's prediction abilities. Many studies over complex terrain point to increasing grid resolution as a means to achieving better agreement of simulations with observations (see e.g. Gronas and Sandvik (1999); Grell et al. (2000); Mass et al. (2003); Chen et al. (2004); Carvalho et al. (2012)), and this should be more important for locally-driven transitions. In contrast, low resolution mesoscale models may be adequate for many situations if the major features of the terrain are simple and adequately captured. The representation of subgrid turbulent motions and sub-grid features in the topography and land use can also play a role in a model's ability to accurately capture wind flow (Hanna and Yang, 2001).

There is uncertainty about the appropriate grid nesting strategy, including selecting adequate turbulence parameterizations and initialization data when moving to high resolution (Wyngaard, 2004). Another major challenge is conserving computational resources, especially when making ultra-high resolution forecasts, for example for predicting ramping events in the next few hours or days. Current models used by wind farm operators use a range 
of resolutions, often coarser than $1 \mathrm{~km}$ horizontally. This begs the question of whether this resolution is fine enough to capture the required flow features or whether computational resources could be saved by using coarser resolution. Accuracy is extremely important to wind power operators as improvements of just $1 \mathrm{~m} / \mathrm{s}$ in wind speed forecasts can mean millions of dollars in savings because of financial penalties for both overestimating and underestimating power production. Suitable model configurations, however, may vary drastically depending on the terrain and other site conditions.

Here we perform simulations at two different sites for which terrain complexity varies greatly to develop insight into the ability to capture shifts in wind speed that are important to wind farm operators. The two sites are chosen to represent opposite ends of the spectrum in terms of terrain complexity, and two extreme types of forcings (locally weak and synoptically strong) are investigated at each site for the results to serve as a possible guide for a broad range of wind farms and forcing conditions. This study is relevant to wind energy forecasting in terms of day ahead forecasting. Short time periods are selected due to the computational cost of simulations at high resolutions. These time periods are chosen to be of interest to the wind industry by including ramping events with synoptic and local forcing to determine the importance of model parameters in each case. After exploring the model parameter space for these cases, a week-long simulation is performed for one group of settings to investigate longer time periods.

We use the Weather Research and Forecasting (WRF) model as our simulation tool (Skamarock and Klemp, 2008). WRF is intended mainly for mesoscale atmospheric simulations and includes large-eddy simulation (LES) 
capabilities. WRF has a fully compressible, Eulerian and non-hydrostatic equation set. Although we focus our study on only two wind farms, the farms are located in regions of high density, high MW wind power installation, making the results from this study meaningful to a large sector of the U.S. wind community. Our complex terrain wind farms are located in a region with at least 5,000 MW of installed capacity, while our simple terrain farm is in an area of at least $700 \mathrm{MW}$ of installed capacity (American Wind Energy Association, 2012).

The simple terrain wind farm, with a 150 MW capacity, covers an area of about $10 \mathrm{~km}$ by $10 \mathrm{~km}$ with a fairly flat topography which includes a few hills with elevation variations of less than $150 \mathrm{~m}$ (see figure 1a). The complex terrain site spans a series of wind farms with over 500 MW installed spread across $37 \mathrm{~km}$ (north-south) by $53 \mathrm{~km}$ (west-east) and features much larger elevation differences of $1500 \mathrm{~m}$ (see figure 1b). Observation data are available from SODARs, meteorological towers, and cup anemometers on the turbine nacelles that can be used for comparison to numerical simulations. Wind speed accuracy is $\pm 0.5 \mathrm{~m} / \mathrm{s}$ for SODAR and $\pm 0.3 \mathrm{~m} / \mathrm{s}$ for cup anemometers. The turbine hub height for both wind farms is $80 \mathrm{~m}$.

[Figure 1 about here.]

The effects of horizontal and vertical grid resolution (section 3.2), 1-way vs. 2-way nesting (section 3.4), and turbulence closure models (section 3.5) are examined here. Results are presented below, along with discussion of the numerical setup and grid nesting approaches. 


\section{Numerical Simulation Setup}

\subsection{Grid nesting and topography}

Four nested grids are used to simulate flow conditions for the wind farms at horizontal resolutions of $8.1 \mathrm{~km}, 2.7 \mathrm{~km}, 900 \mathrm{~m}$, and $300 \mathrm{~m}$. The main features of the topography become visible at $2.7 \mathrm{~km}$ for the simple terrain case and $900 \mathrm{~m}$ for the complex terrain, but fine structures become much better resolved at $100 \mathrm{~m}$ resolution for both cases (figure 1). Topography was extracted from a $10 \mathrm{~m}$ resolution data set available from the USGS. The terrain is smoothed near the boundary for each nested sub-domain to match the elevations for the surrounding coarser grid. WRF uses a terrainfollowing, hydrostatic-pressure vertical coordinate system with the top of the model being a constant pressure surface. The vertical grid spacing is normally assigned by default by WRF, or it can be specified by the user to decrease spacing near the bottom of the model and stretch it near the top. The minimum vertical grid spacing $\left(\triangle z_{\min }\right)$ at the surface, as well as the average spacing $\left(\triangle z_{\text {avg }}\right)$, are listed in table 1 for the grid configurations used. The domain height is approximately $13 \mathrm{~km}$ for the simple terrain case and $18 \mathrm{~km}$ for the complex terrain case to allow a larger damping region at the top of the domain (thus also requiring more vertical levels). The grids for the complex terrain site are larger so as to include more surrounding topographic features; the simple terrain site is not near any significant topographic features which would warrant a larger domain. Larger domains have been tested but have not shown any significant differences (not shown). This model setup is fairly standard for a nested WRF simulation. All the nested domains are the same size and centered within each other. 
[Table 1 about here.]

Several challenges are encountered with WRF over complex terrain. The terrain-following coordinates are considerably distorted near the surface over steep terrain which leads to numerical instability in the model. Reducing the time step, smoothing the terrain, and decreasing the vertical resolution near the ground were all attempted but resulted in significant distortion or excessive run time. The most effective option in our case is to adjust the time off-centering in WRF that weights (forward in time) the vertically-implicit acoustic-time-step terms in the model to damp instabilities associated with sound waves and sloping model levels (Durran and Klemp, 1983; Dudhia, 1995). The off-centering is accomplished by using a non-zero, positive coefficient in the acoustic time-step vertical momentum equation and geopotential equation.

\subsection{Computational time}

The computational time for these simulations is reasonable for shortterm forecasting applications. The smaller simple terrain site needed about 9 hours of wall time for a 48 hour simulation, while the complex terrain site needed about 43 hours of wall time for a 48 hour simulation. Simulations for both sites used 144 processors for the 4 concurrently simulated domains (1:3 nesting ratio used for horizontal and temporal resolutions).

\subsection{Initialization and lateral boundary conditions}

Initial and boundary conditions were obtained from the National Center for Atmospheric Research (NCAR) North American Regional Reanalysis 
(NARR) data. NARR is available at $32 \mathrm{~km}$ horizontally at 29 vertical levels (1000-100hPa; excluding surface) to force the WRF simulations at the coarsest grid. Lateral boundary condition forcing was applied at three-hour intervals and linearly interpolated in between. Relaxation towards the lateral boundary values was applied around the edge of the domain. Simulations were performed for 48 hours for the short term events and for an extra 120 hours for the week-long statistical analysis. Output was stored at ten-minute intervals and used to generate initial and boundary conditions for the nested grids. Simulations using NAM for initialization were also performed, but the overall conclusions were similar (not shown).

\subsection{Surface characteristics}

WRF uses 33 land use categories (including ice and water) from USGS. The simulations use National Land Cover Database (NLCD) data at $30 \mathrm{~m}$ resolution which is mapped from the native 19 land use categories to the USGS 33 land use categories. The Noah Land Surface Model was used with initial moisture and soil temperature in four layers interpolated from NARR. Land-atmosphere coupling effects on the boundary layer, such as soil moisture initialization, can have a significant effect on simulation results, and at finer resolutions it may be necessary to use finer-scale soil initialization fields (Woodward et al., 2009; Williams et al., 2009; Chow et al., 2006). Section 3.3 examines the role of soil moisture on the model results.

\subsection{Turbulence}

WRF provides several turbulence closure options for the Reynolds-Averaged Navier Stokes (RANS) equations of motion. These closures are referred to 
as Planetary Boundary Layer (PBL) schemes and they parameterize vertical turbulence diffusion (or vertical mixing) in physical space. All the PBL schemes make use of second order horizontal diffusion on the model levels, where gradients are simply taken along coordinate surfaces. The horizontal eddy viscosity is determined from horizontal deformation using a Smagorinsky first-order closure approach.

Several of the PBL schemes use a prognostic turbulence kinetic energy (TKE) closure that predicts the sub-grid TKE using a TKE equation to obtain the vertical eddy viscosity. These include the base case MellorYamada-Janjic (MYJ) scheme (Janjic, 1994), the Quasi-Normal Scale Elimination (QNSE) PBL (Sukoriansky et al., 2005), the Mellor-Yamada Nakanishi and Niino Level 2.5 (MYNN2) and 3 (MYNN3) PBLs (Nakanishi and Niino, 2006), the Bougeault-Lacarrere (BouLac) PBL (Bougeault and Lacarrere, 1989), the University of Washington (UW) scheme (Park and Bretherton, 2009), and the Grenier-Bretherton-McCaa (GBM) scheme (Grenier and Bretherton, 2001). Unlike the prognostic TKE PBLs, the Yonsei University (YSU) scheme (Hong et al., 2006) and its predecessor, the Medium-Range Forecast (MRF) model (Hong and Pan, 1996), are both non-local vertical eddy viscosity schemes. The Asymmetric Convective Model (ACM2) (Pleim, 2007) uses a hybrid approach with non-local upward mixing and local downward mixing. The Total Energy Mass Flux (TEMF) scheme (Angevine et al., 2010), which uses a sub-grid total energy prognostic variable with mass-flux type shallow convection, is also tested, but is numerically unstable for the synoptically-forced complex terrain case and is not compared in this work. All the PBL schemes compared in this work (see section 3.5) make use of the 
Noah land surface model and use the recommended surface-layer physics option in WRF (which is particular to each PBL scheme). ACM2 makes use of the MM5 Monin-Obukhov surface-layer scheme instead of its recommended surface-layer scheme, because the recommended scheme is designed for the Pleim-Xiu land surface model (which is not used in this study).

\section{COMPARISON WITH OBSERVATION DATA}

Results comparing simulations with observation data for the two-day events are given in this section. Four main cases will be described: a locallyforced and a synoptically-forced case for both the simple and complex terrain. These events occur during four different selected time periods. The naming convention for each case is explained in table 2, along with a brief description of the ramping. Case CTL does show rapid changes in wind speed, but the magnitude of the wind speed is too low to consider any of these changes ramping events by our definition of a $7 \mathrm{~m} / \mathrm{s}$ wind speed change.

\section{[Table 2 about here.]}

For each simulation period, a number of different model configurations is tested, using different resolutions, grid nesting, vertical levels, and turbulence closure models. The naming convention for these runs is "(finest horizontal resolution)_(number of points in vertical)", as shown in table 3. Note that the base case simulation for the simple terrain (ST) site uses 49 vertical levels, while the base case simulation for the complex terrain (CT) site uses 54 vertical levels due to the different domain heights. All the results are from 1-way nesting and the Mellor-Yamada-Janjic turbulence model unless 
otherwise noted. The week-long simulations (section 3.6) are an extension of their respective short-term cases for 5 additional days.

[Table 3 about here.]

\subsection{Comparison strategy}

A Doppler mini SODAR (Model4000, Atmospheric Systems Corporation, Santa Clarita, CA) collected high vertical resolution, three-axis wind velocity data at a $1 \mathrm{~Hz}$ per beam sampling resolution. SODAR data were averaged over 10-minute intervals to calculate mean horizontal and vertical wind speed, direction, latitudinal, longitudinal and vertical turbulence intensities, and turbulence kinetic energy at 10 meter intervals at heights 20-200 m above ground level (AGL). The data was quality controlled according to accepted SODAR standards (e.g. Antoniou et al. (2003)) (see Wharton and Lundquist (2012)). SODAR 10-minute intervals are compared with instantaneous model output at 10 minutes.

The time series and profile figures in the next few sections are located at the SODAR site, at the center of each domain, and are representative of other locations in the domain. SODAR data are available at 10 meter intervals from 20-200 m AGL, however at elevations above $100 \mathrm{~m}$ the data are sparse. To quantify the comparisons, error tables (such as table 4) show the rootmean-square errors (RSME) and mean absolute errors (MAE) between the SODAR data and the simulations over 20-200 m above the ground, averaged over 48 hours. They are defined as:

$$
M A E=\frac{1}{M} \sum_{j=1}^{M} \frac{1}{N} \sum_{i=1}^{N}\left|A_{i, j}-B_{i, j}\right|
$$




$$
R M S E=\sqrt{\frac{1}{M} \sum_{j=1}^{M} \frac{1}{N} \sum_{i=1}^{N}\left(A_{i, j}-B_{i, j}\right)^{2}}
$$

where $M$ is the number of time steps; $N$ the number of vertical grid points; $A$ observation data; and $B$ simulation data. RMSE and MAE may be insufficient for evaluating model performance during ramp events, although industry practice still heavily relies on these metrics. Newer techniques, including the critical success index, need to be further developed and studied to evaluate ramp forecasts (Marquis et al., 2011). The evolution of wind speed and wind direction during these events is presented in figures (such as figure 3) comparing different cases at $80 \mathrm{~m}$ AGL. The observations are, in most sections, compared to 1-way nested run resolutions: 300m (4 grid nests), 900m (3 grid nests), 2700m (2 grid nests), and 8100m (1 grid).

\subsection{Effects of resolution}

\subsubsection{Topography resolution}

The required grid resolution depends greatly on the nature of the local topography. The chosen horizontal resolutions (see table 1) seem to easily capture the topography of the simple terrain site. Figure 2a shows how all the resolutions, fine and coarse (except for the $8100 \mathrm{~m}$ case), capture the hill and general topography of the wind farm quite well. Conversely, it is not as easy to capture the terrain of the complex topography site (figure 1b). Figure $2 \mathrm{~b}$ indicates that the coarser horizontal resolutions $(8100 \mathrm{~m}$ and $2700 \mathrm{~m})$ do not capture the complexity of the terrain, but the finer resolutions do.

[Figure 2 about here.] 


\subsubsection{Effects of horizontal resolution during locally-forced events}

We first examine locally-forced events over simple (Case STL) and complex terrain (Case CTL) and compare output from 1-way nested runs to evaluate the impact of grid resolution. Case STL shows an increase in wind speed on the first day at 16 UTC that is slightly more gradual and starts earlier than what is shown by the SODAR and does not capture the minimum wind speeds observed by the SODAR (see errors in table 4 and figure 3a). The down-ramping event on day 2 from 13 UTC to 16 UTC, where the wind speed decreases from $10.5 \mathrm{~m} / \mathrm{s}$ to $3 \mathrm{~m} / \mathrm{s}$, is well captured by the simulations when compared to the observations, however, the minimum of the ramp is not. Case CTL corresponds well with the SODAR for most of the first day including the increase in wind speed from 17 UTC to the end of the day, but fails to capture the lower wind speeds the observations show for the second day and instead shows a large increase in wind speed.

The difference in performance for the various grid resolutions for Case STL is small, as seen in the error metrics listed in table 4 . The results are very similar across all resolutions with the finest producing a slightly smaller error than the coarser ones preceding it. This is somewhat surprising as we expected to see more distinct differences between the resolutions. The vertical profiles in figures 4a and 4b show time slices at the SODAR location from two different times, with varying levels of agreement with the SODAR. Under these conditions relatively coarse horizontal resolution $(2.7 \mathrm{~km})$ appears to be adequate for capturing the shift in wind speed at the wind turbine hub heights ( $\sim 80-100 \mathrm{~m})$ for Case STL as there is little improvement for the finer resolutions. These results agree with other simulations such as those 
from Yver et al. (2013), which showed improvement from $12 \mathrm{~km}$ horizontal resolution to $4 \mathrm{~km}$ but not from $4 \mathrm{~km}$ to $0.8 \mathrm{~km}$ for a California coastal area. Deppe et al. (2012) did not register any improvement from $10 \mathrm{~km}$ to 4 $\mathrm{km}$ horizontal resolution for their simple terrain site in Iowa. The terrain is adequately resolved on all grids in the simple terrain case and the mean flow patterns are very similar.

The dependence on grid resolution for Case CTL is much more significant as the error metrics show in table 4 . In this case the two finer resolutions (900 and $300 \mathrm{~m}$ ) compare better to the SODAR observations than the two coarser resolutions, as shown in figures $3 \mathrm{c}$ and $3 \mathrm{~d}$. The improvement from $8100 \mathrm{~m}$ to $2700 \mathrm{~m}$ resolution is most noticeable, while improvement from $2700 \mathrm{~m}$ to 900 $\mathrm{m}$ is less and $900 \mathrm{~m}$ to $300 \mathrm{~m}$ even less. The vertical profiles in figures $4 \mathrm{c}$ and 4d show two different time slices at the SODAR location; Case CTL shows a clear advantage to using high resolution simulations during certain times of the day, particularly resolution finer than $8100 \mathrm{~m}$. It is worth noting in the vertical profiles (figure 4) that WRF may not always accurately capture the magnitude, but does somewhat more accurately represent the vertical wind shear profile. More accurate comparisons to the SODAR are observed with finer resolution in complex terrain because the details of the topography are better resolved, which can dramatically influence winds.

Case STL seems to predict wind speeds close to those of the SODAR but the timing is slightly off for the increased wind speed event that starts at 16 UTC on the first day and wind speeds are over-predicted just before the increase when comparing to observations. While there is clear improvement with higher resolution in the first hours, Case CTL over-predicts wind speeds 
after the first 25 hours of the simulation and skews MAE and RMSE calculations so that the finest resolution does not give the lowest value. Errors calculated separately for just the first day show much smaller values (table 4). These inaccuracies are later found to be at least partially attributed to misrepresentation of soil moisture in WRF (see section 3.3).

[Figure 3 about here.]

[Figure 4 about here.]

[Table 4 about here.]

\subsubsection{Effects of vertical resolution during locally-forced events}

Vertical spacing may have a significant effect on the accuracy of wind speed and direction predictions, particularly when wind shear is strong, e.g. in the case of nocturnal low level jets which can also be responsible for ramping events (see e.g. Storm et al. (2009)). To examine the need for high vertical resolution in high-shear regions, 4 sets of grids (with 1-way nesting) are examined. The grids were generated as follows: 300m_49 (and 300m_54) uses a tanh function to stretch the vertical grid spacing so that there is minimum spacing near the ground of 30 meters which is stretched higher up into the atmosphere; 300m_70 uses specified grid levels that provide spacing of about $10 \mathrm{~m}$ in the lowest $200 \mathrm{~m}$ of the atmosphere and then stretched above (for Case STL) or start at $10 \mathrm{~m}$ and are stretched above (for Case CTL); 300m_40 is created by specifying 40 levels in WRF and using the default spacing (the minimum spacing is $\sim 55 \mathrm{~m}$ and average spacing is $\sim 309 \mathrm{~m}$ ). Figure 5 shows the evolution of wind speed. Table 5 shows 
the RMSE and MAE between simulations and observations along with the average vertical spacing in the range where observation data exists (20-200m). Surprisingly, the grids all give very similar results for the Case STL ramping event, with the lower resolution $300 \mathrm{~m} \_40$ providing slightly worse results. The less computationally intense option in this case appears adequate for predicting ramping. This agrees with other studies such as Floors et al. (2013), which compared 41 vertical levels against 63 vertical levels within lidar range over the simple terrain coast of Denmark and found almost no improvement with vertical resolution.

Case CTL shows quite a bit more variation with vertical resolution. Table 5 appears to show that the WRF chosen 40-level setup gives the most accurate results followed by the 70 vertical levels stretched case, and finally the 54-level tanh stretched case. However, if the second day (during which the simulations over-predict the wind speed due to land-surface conditions mismatch between WRF and observations [discussed in section 3.3]) is excluded, the different resolutions seem to perform similarly, with the two finest vertical resolutions outperforming the coarser resolution. This suggests that for locally-forced complex terrain cases the results benefit slightly from an increase in the number of vertical levels used. The differences from changing the vertical resolution appear less significant than the horizontal resolution effects described above. Zhang et al. (2013) and Talbot et al. (2012) made similar conclusions from their simulations over complex terrain, where increased vertical resolution improved comparisons to observations to some degree, but not as significantly as horizontal resolution.

[Figure 5 about here.] 
[Table 5 about here.]

\subsubsection{Effects of horizontal resolution during synoptically-forced events}

In this section we compare the effects of horizontal resolution in simulating the two synoptically-forced events. Once again output is compared from 1-way nested runs to evaluate the impact of grid resolution for both simple and complex terrain. The SODAR observations of the evolution of wind speed $80 \mathrm{~m}$ above the surface are presented for Case STS (figure 6a) and Case CTS (figure 6b). Simulations for Case STS compare rather well with the SODAR observations at all resolutions as the errors in table 6 show. All resolutions accurately capture the major ramping event at 18 UTC to 21 UTC on the second day, where wind speed increases from $4 \mathrm{~m} / \mathrm{s}$ to $16 \mathrm{~m} / \mathrm{s}$, and match the observations quite well over the rest of the simulation. A cold frontal passage results in the increase in wind speeds for Case CTS at about 12 UTC on the first day and passes the next day at about 12 UTC as the ramping indicates. The simulation for Case CTS corresponds with SODAR observations with almost all grid resolutions as the error comparison in table 6 indicates. The simulations are slightly off in capturing the large ramping event on the first day from 10 UTC to 12 UTC, where wind speed increases from $10 \mathrm{~m} / \mathrm{s}$ to $20 \mathrm{~m} / \mathrm{s}$. The largest differences between the resolutions are observed at 2 UTC on the second day, but there is no observation data for that time period. The MAE error for Case CTS of around $3.5 \mathrm{~m} / \mathrm{s}$ is likely due to a forcing problem (initial/boundary conditions) because the different resolutions give very similar results for quite complex terrain. Most of the errors occur at the ramp up or after the cold front. Zhang et al. (2013) also found that the magnitude of errors is generally greater in the strong forc- 
ing than weak forcing cases as the errors appear more closely related to the influence of the weather systems.

It is of note that noticeable differences are observed with grid resolution for the complex terrain case during local forcing (section 3.2.2) but not during synoptic forcing. It may be that lateral boundary condition errors dominate under strong synoptic forcing. It is not surprising that Case STS does not show any improvement with increased resolution when Case STL did not show any either due to the ease with which the various resolutions capture the simple terrain. Furthermore, the simulations for the synoptically-forced cases do not deviate as much from the observations as the locally-forced cases discussed previously. The strong synoptic forcing likely dominates over any other local forcing parameters that might have a significant effect on the wind fields such as soil moisture variation.

[Figure 6 about here.]

[Table 6 about here.]

\subsection{Effects of land-surface conditions during locally-forced events}

Overall, there appear to be relatively small differences between results from different grid configurations except for the locally-forced complex terrain (CTL) case, as described above. Both locally-forced events, however, showed large errors when compared to SODAR observations. This is especially true in capturing the lower wind speeds at hub height ( $~ 80 \mathrm{~m})$, so there is certainly room for improvement in the simulations. Here we examine the effect of land-surface forcing for Cases STL and CTL. These simulations are designed to test the role of soil moisture in the locally-forced cases, which 
are anticipated to be more sensitive to land-surface forcing (Chow et al., 2006). Two soil moisture extremes are compared to the base case for both locally-driven terrain cases. In one extreme, the initial soil moisture value is set to 90 percent or almost fully saturated for the whole domain and left to adjust in time according to soil type. In the other extreme, the soil moisture value is initialized at 0.02 percent or almost completely dry for the whole domain. Figure 7a shows that when the soil for Case STL is initialized as dry, it over-estimates the wind speeds slightly more than the base case. When Case STL is initialized as saturated, however, it is much better able to match the full extent of the down-ramping at 16 UTC on the second day, while not capturing the later peaks as well. For the complex terrain domain, figure $7 \mathrm{~b}$ shows that saturated initial conditions for Case CTL yield results similar to the base case. The dry soil initialization, 300m_54_dry, however, captures the minima of the SODAR much better for the second day. The dry case shows reduced error when compared to the base and saturated cases as shown in table 7 . The surface energy fluxes can be drastically affected by the soil moisture and strongly influence wind speeds at hub-height. This suggests that hub-height winds are sensitive to soil moisture and that accurate representation of land-surface conditions may be just as important for accurate simulations in this case, rather than just looking at differences in resolution or other model configuration parameters.

[Figure 7 about here.]

[Table 7 about here.] 


\subsection{Difference between 1-way and 2-way nesting}

In 1-way nesting, the finer domains do not influence the parent domains. With 2-way nesting, the finer grid feeds information back to the coarser parent domain. The coarser grid is then updated with higher resolution fields which theoretically leads to a more accurate simulation result. 2-way nesting is thought to be important when fine-scale features that are resolvable on the finer domain affect meteorological conditions on a larger scale. Harris and Durran (2010) found that 2-way nesting is in general superior to 1-way nesting in an idealized comparison of the linear 1-D shallow-water model. 1-way nesting performs better only when very poorly resolved waves strike the nest boundary. Liu et al. (2011) tested WRF-LES for wind energy with data assimilation over real terrain and compared 1-way and 2-way nesting. They found that, in general, 2-way nesting agrees best with the observations. Figure 8 shows time series of wind speed for the 1-way nested base case and the 2-way nested case each with the same four nesting levels. Under strong synoptic-scale forcing, it is likely that 1-way nesting will be adequate for feeding information from the larger scales to the finer scales. Case STL (simple terrain locally-driven forcing) in figure 8a shows an insignificant difference between 1-way and 2-way nesting even with local forcing. The similarity is most likely due to the negligible benefit of finer horizontal resolution (see section 3.2.2) for this case that results from the simplicity of the topography. Case CTL (complex terrain locally-driven forcing), in figure 8b, shows a noticeable improvement with 2-way nesting when compared to the 1-way nested base case. Table 8 quantifies these differences and indicates that the terrain at finer resolutions affects the coarser domain results be- 
cause improvement with higher resolution is observed in this case due to the complexity of the terrain. There is little difference between 1-way and 2-way nesting for both synoptically-forced simulations, Cases STS and CTS, where the strong synoptic forcing overwhelms any local influences on winds due to terrain complexity.

[Figure 8 about here.]

[Table 8 about here.]

\subsection{Comparing WRF Planetary Boundary Layer (PBL) schemes}

Other works have examined the effects of Planetary Boundary Layer (PBL) schemes in WRF (see section 2.5 above for descriptions) and most have found that no single PBL scheme can be recommended for all circumstances as each scheme has its own strengths and weaknesses (Zhang et al., 2013; Yver et al., 2013). Xie et al. (2013) compared two nonlocal mixing schemes, YSU and ACM2, with two local mixing PBL schemes, MYJ and MYNN2, at $3 \mathrm{~km}$ horizontal resolution over Southeast England for numerous stability conditions. They found that local PBL schemes considerably underestimate the entrainment heat fluxes for convective cases, while the nonlocal schemes exhibit stronger mixing and agree better with large-eddy simulation studies. However, the $10 \mathrm{~m}$ wind speed RMSE values for the four schemes for the months of June and November vary by less than $0.1 \mathrm{~m} / \mathrm{s}$ and were quite similar for all the cases. Yver et al. (2013) compared 4km horizontal resolutions of the YSU, MYJ, QNSE, MYNN2, ACM2, BouLac, UW, and TEMF schemes over a one month period along the California Coast and found that 
all the schemes present similar results and generally agree with the observations. Xie et al. (2012) compared the YSU, ACM2, MYJ, and BouLac PBL schemes over Hong Kong for June and November at $1 \mathrm{~km}$ resolution. The $10 \mathrm{~m}$ wind speed RMSE showed that ACM2 and YSU perform slightly better than MYJ and BouLac by about $0.25 \mathrm{~m} / \mathrm{s}$. Most other works looked at wind speed comparisons near the surface at $10 \mathrm{~m}$ elevation, where surface friction effects are strong, because of the availability of data, but Deppe et al. (2012) compared the YSU, MYJ, QNSE, MYNN, and ACM2 PBL schemes with ensemble simulations at turbine hub height $(80 \mathrm{~m})$ in Iowa at $10 \mathrm{~km}$ horizontal resolution. They found that nonlocal schemes (YSU and ACM2) overall performed better than local PBL schemes (MYJ, QNSE, MYNN) by MAE differences of about $0.15 \mathrm{~m} / \mathrm{s}$ on average for month long simulations. Here we compare almost all the PBL schemes available in WRF at turbine hub height at fine horizontal and vertical resolution and at the simple and complex terrain sites.

Figure 9 shows how the different PBL schemes in WRF perform in each of the four cases tested at $300 \mathrm{~m}$ horizontal resolution. The RMSE for each case (STL, STS, CTS, and CTL) along with the average of all the cases (Total AVG) is shown for each PBL scheme. The average of all the cases (Total AVG) is calculated based on the time duration of each case (Case CTL has half the weight of the other cases because we only consider the first 24 hour period for which the results are reasonable and not the full 48 hours). The PBL schemes are ordered along the $\mathrm{x}$-axis from lowest case average RMSE to highest case average RMSE (left to right) with the average RMSE indicated below the PBL scheme name in units of meters per second. 
The GBM PBL scheme performs the best with the lowest averaged RMSE of $2.54 \mathrm{~m} / \mathrm{s}$ compared to the base case MYJ PBL scheme, which is third best with an average RMSE of $2.74 \mathrm{~m} / \mathrm{s}$. The PBL schemes all seem to perform rather similarly with less than $0.14 \mathrm{~m} / \mathrm{s}$ RMSE separation between each scheme, except for the poor performance from the MRF PBL which is $0.28 \mathrm{~m} / \mathrm{s}$ worse than the second to worst performer (YSU). MRF is a legacy PBL scheme in WRF and is improved on by YSU. Neglecting MRF, the different PBL schemes differ less than an average RMSE of $0.5 \mathrm{~m} / \mathrm{s}$ for the tested cases, though this difference could be significant from a forecasting perspective. The TKE based PBL schemes seem to cluster together and overall outperform the non-local vertical eddy viscosity schemes (YSU and MRF), which perform the worst. The ACM2 scheme, which uses a hybrid approach, places fourth overall with an average RMSE of $2.78 \mathrm{~m} / \mathrm{s}$.

Certain PBL schemes perform better for specific cases. GBM does particularly well for Case CTS, however, all the schemes have their highest RMSE error for this case. MYJ has the lowest RMSE for Case CTL, and all the PBL schemes have their lowest RMSE error for this case except MRF. ACM2 does best for Case STL along with the MYNN schemes, and UW outperforms the others for Case STS. The PBL schemes, for the most part, do not show any significant improvement from $2700 \mathrm{~m}$ to $300 \mathrm{~m}$ horizontal resolution for all the cases except Case CTL. The average RMSE improvement, if any, for Cases STL, STS, and CTS does not exceed $0.025 \mathrm{~m} / \mathrm{s}$ with the largest single improvement for a scheme not exceeding $0.18 \mathrm{~m} / \mathrm{s}$ (QNSE for Case STL, with MYJ's $0.08 \mathrm{~m} / \mathrm{s}$ improvement coming in second). MRF is the only exception with a $0.6 \mathrm{~m} / \mathrm{s}$ improvement for Case CTS, but this scheme performs much 
worse than any other scheme in this case (QNSE's $0.11 \mathrm{~m} / \mathrm{s}$ improvement is second highest). The PBL schemes show more significant improvement with resolution for Case CTL with an average RMSE improvement of $0.39 \mathrm{~m} / \mathrm{s}$. The largest improvement is $0.66 \mathrm{~m} / \mathrm{s}$ for GBM and YSU, while the smallest improvement is $0.16 \mathrm{~m} / \mathrm{s}$ for $\mathrm{UW}$.

It is difficult to recommend one PBL scheme for every situation, but general guidelines can be extracted from this comparison. The TKE based PBL schemes clearly outperform the non-local vertical eddy viscosity schemes. MRF has a significantly higher average RMSE than the rest of the schemes and this is mostly a result of its particularly poor performance for the complex terrain cases. While its RMSE is closer to average for the simple terrain cases, it is never in the top four PBL schemes. It is not recommended to use the MRF PBL scheme for wind energy applications. YSU's average RMSE error is closer to the other PBL schemes than MRF's, but it too never rates better than fifth place for any of the cases. However, it does not show the large errors associated with MRF for the complex terrain cases and might be an acceptable alternative for cases in which computational resources are limited, because it does not calculate the TKE equation. It is still not recommended for periods dominated by stable conditions, because the use of a non-local eddy viscosity scheme is not best suited to cases where the turbulent eddies are of a smaller scale than the vertical grid spacings of the model (Pleim, 2007). ACM2 is a top performer in this study, especially for Case STL. It is able to switch between stable conditions (local eddy diffusion as in MYJ) and unstable conditions (local and nonlocal transport). MYJ, the base case, performs respectably by coming in third overall with an average 
RMSE of $2.74 \mathrm{~m} / \mathrm{s}$ and does particularly well for Case CTL. It is a good base case choice because it makes use of the TKE equation and is the second oldest scheme implemented into WRF after MRF.

[Figure 9 about here.]

\subsection{Effects of grid resolution on week-long simulations}

In addition to short-term forecasts, there is interest in longer-term performance of simulations to assist with forecasting and wind resource characterization. A week-long simulation is performed using the locally-driven simple and complex terrain test cases to further examine grid resolution effects on predicted disturbances of wind speed and turbulence intensity distributions for a specific site. The simulation is for 7 days after the start of Case STL and Case CTL respectively. Changes in long-term distributions could be useful for more detailed site evaluations for turbine placement.

\subsubsection{Week-long results for wind speed}

The results obtained from week-long simulations for horizontal wind speeds fall in line with the shorter term 48 hour simulations. The finer resolution runs for Case STL show little variation in wind speed distributions from the coarser resolutions as shown in the probability density function (PDF) in figure 10a though there is an advantage to using $2700 \mathrm{~m}$ or finer grid spacing for representation of faster, less frequent winds as suggested in the error metrics (table 9). The PDFs are created at hub height above ground and binned into 18 equally spaced bins that span the minimum and maximum range for each category at the SODAR location during a week of summer. 
They all show, along with the SODAR, that during this summer week, wind speeds are rather high and favorable for producing wind energy.

The week-long simulations for Case CTL also show similar results compared to the shorter term 48 hour simulations. Figure 10b and table 9 show improvement with higher resolution, though the improvement beyond 900 $\mathrm{m}$ is small. Zhang et al. (2013) looked at errors in $10 \mathrm{~m}$ surface wind from WRF simulations in complex terrain for both 3 day and month long simulations for horizontal resolutions ranging from 27 to $1.11 \mathrm{~km}$. They found that higher resolution simulations do not outperform coarser simulations in many cases most likely because of the inability of the numerical model to depict near-surface structures even with better terrain representation. Yver et al. (2013) also found that there is improvement in month-long simulations from $12 \mathrm{~km}$ to $4 \mathrm{~km}$ horizontal resolution, but not from $4 \mathrm{~km}$ to $0.8 \mathrm{~km}$.

[Figure 10 about here.]

[Table 9 about here.]

\subsubsection{Week-long results for turbulence intensity}

Turbulence intensity is also vital to consider in determining potential wind farm locations, because a value that is too high (roughly greater than $20 \%$ of the mean wind speed) will result in feathered wind turbines to avoid damage (and hence a loss in power production). The definition of turbulence intensity is:

$$
T I=\frac{\sqrt{\sigma_{u}^{2}+\sigma_{v}^{2}+\sigma_{w}^{2}}}{U_{\text {mean }}}
$$


where $U_{\text {mean }}$ is the average horizontal wind speed over a time period, $\sigma_{u} ; \sigma_{v} ; \sigma_{w}$ are the standard deviations of wind speed over that same time period in the East-West, North-South, and vertical directions respectively. The turbulence intensity for the SODAR is calculated by averaging the wind speed at every recorded second over a 10 minute period and calculating the standard deviation of each component of wind speed. The turbulence intensity for the simulations is obtained using WRF's output of TKE from MYJ, $\frac{\sqrt{T K E}}{U}$.

As figure 11a shows, there is little difference in the distribution of TKE among the various resolutions (except the coarsest $8100 \mathrm{~m}$ case) for Case STL. They all show similar results and estimate probability areas close to the SODAR. The peaks for the turbulence intensity are slightly off, with the simulations predicting slightly lower turbulence intensity when compared to the SODAR. However, as the number of bins increases the peaks come closer together. This site seems to be almost ideal during this particular time of year for wind turbines, as turbulence intensity only exceeds $20 \%$ less than $4 \%$ of the week.

The week-long simulations for Case CTL, shown in figure 11b, appear to greatly under-predict turbulence intensity for the time period. The finer resolutions are slightly better compared to the SODAR observations and predict a greater occurrence of higher turbulence intensity for the week. Overall, the simulations seem to under-predict higher instances of turbulence intensity. This could be a problem when evaluating potential turbine siting locations, as Case CTL shows the simulations predict turbulence intensity exceeding $20 \%$ only about $20 \%$ of the week while observations show this threshold ex- 
ceeded about $75 \%$ of the week. It is important to note that the SODAR turbulence measurements have a degree of uncertainty. These uncertainties generally bias the turbulence intensity magnitudes towards higher values (see Wharton and Lundquist (2012) for full discussion). The observations show more instances of low wind speed than the simulations (figure 10b); this may be why turbulence intensity for the observations is much higher than for the simulations, because for the same standard deviations of the wind speed components, lower wind speed (see denominator of equation 1 above) results in higher turbulence intensity even when there may not be more turbulence. However, even when wind speeds are higher for both (as in Case STL), the simulations still seem to under-predict turbulence intensity. The results for both cases show a higher frequency of low turbulence intensity than the observations indicate. Most of these values appear to correspond to the minimum turbulent kinetic energy (TKE) $\left(0.1 \mathrm{~m}^{2} / \mathrm{s}^{2}\right)$ set in the MYJ model. This agrees with Xie et al. (2013), who found that MYJ appears to under predict TKE when compared to observations and MYNN. These results suggest that there is room for improved turbulence closures for wind turbine siting purposes.

[Figure 11 about here.]

\section{Conclusion}

There is increasing demand to provide higher resolution, high precision, forecasts of winds for wind energy applications. Little guidance exists to aid numerical modelers as they push numerical weather prediction models to their limits. This paper illustrates the sensitivity, or lack thereof, of the 
numerical results to various model configuration parameters. Case study simulation results were presented using WRF to capture both synoptically and locally-driven events at two different sites where terrain complexity varies greatly to develop preliminary insight into the ability to capture shifts in wind speed that are important to wind farm operators.

The effects of grid resolution, 1-way vs. 2-way nesting, turbulence closure models, and week-long simulation results were examined in this paper. Large changes in wind speed were reasonably represented with all grid resolutions and grid nesting configurations tested for the simple terrain simulations (Cases STL and STS). These results are counter-intuitive when considering general recommendations to use higher resolution. Given the simple terrain of this wind farm it may be concluded that resolution does not necessarily bestow the benefit of increased accuracy. There was improvement with higher resolution and 2-way nesting when simulating a locally-forced event over complex terrain. Terrain as complex as at the complex terrain site discussed in this paper warrants higher resolution simulations to predict winds, especially during weak forcing. During strong synoptic forcing, the complex terrain site showed minimal sensitivity to grid resolution, indicating that the forcing greatly dominates over local topographic influences. This suggests that computational resources may be spared by wind farm operators and forecasters if the site consists of simple terrain or even in certain cases with synoptic forcing over complex terrain. Simulations at high resolution could be most important in complex terrain and under local forcing.

It is of interest to note that the synoptically-driven events were better simulated (compared to observation data) than the locally-driven events for 
both wind farms; this is expected because the strong synoptic forcing in most cases overshadows other parameters. Land-surface parameters had more of an effect on the simulation results than resolution or the options used for turbulence closure during the locally-forced events, as demonstrated here by varying soil moisture conditions. Initialization conditions could be responsible for errors in the simulation results in some cases. It is difficult to recommend one PBL scheme that works best for every situation. The choice of a PBL scheme for a certain case may vary significantly depending on the meteorological forcing and terrain. On average, the prognostic TKE equation schemes gave more accurate results when compared to observations (particularly GBM, UW, and MYJ). The non-local vertical eddy viscosity schemes (YSU and MRF) performed worse on average, most likely due to their weakness during strongly stable situations, but YSU might be acceptable in some cases in which computational resources are limited. Week-long simulations showed similar results to the short-term simulations. The MYJ turbulence closure seemed to consistently under-predict turbulent kinetic energy in both cases.

\section{Acknowledgements}

The authors express great appreciation to Iberdrola Renewables, Inc. for the collection, provision, and insightful discussion of the wind farm datasets. The authors also thank Julie Lundquist for initiating this project. This work is funded by the Department of Energy's Wind and Water Power Program Office under the Renewable Systems Interconnect Support program (BNR Code EB2502010) and the Lawrence Scholar Program. LLNL is operated by 
Lawrence Livermore National Security, LLC, for the DOE, National Nuclear Security Administration under Contract DE-AC52-07NA27344. IM release number: LLNL-JRNL-611332.

\section{References}

American Wind Energy Association, 2012. Wind Energy State Fact Sheets 2012. Technical Report. American WInd Energy Association. URL: http://www. awea.org/learnabout/publications/factsheets/factsheets_state.cfm.

Angevine, W.M., Jiang, H., Mauritsen, T., 2010. Performance of an eddy DiffusivityMass flux scheme for shallow cumulus boundary layers. Monthly Weather Review 138, 28952912. URL: http://dx.doi.org/10.1175/2010MWR3142.1, doi:10.1175/2010MWR3142.1.

Antoniou, I., Jorgensen, H., Ormel, F., Bradley, S., Hunerbein, S.V., Emeis, S., Warmbier, G., 2003. On the theory of SODAR measurement techniques (final reporting on WP1, EU WISE project NNE5-2001-297). Project Report. Riso. Roskilde, Denmark. URL: http://usir.salford.ac.uk/9588/.

Bougeault, P., Lacarrere, P., $1989 . \quad$ Parameterization of orography-induced turbulence in a mesobeta-scale model. Monthly Weather Review 117, 1872-1890. URL: http://dx.doi.org/10.1175/1520-0493(1989)117<1872:P0OITI>2.0.C0;2, doi:10.1175/1520-0493(1989)117¡1872:POOITI¿2.0.CO;2. 
Carvalho, D., Rocha, A., Gomez-Gesteira, M., Santos, C., 2012. A sensitivity study of the wrf model in wind simulation for an area of high wind energy. Environmental Modelling amp; Software 33, 23 - 34. URL: http://www.sciencedirect.com/science/article/pii/S1364815212000382, doi:10.1016/j.envsoft.2012.01.019.

Chen, Y., Ludwig, F., Street, R., 2004. Stably stratified flows near a notched transverse ridge across the salt lake valley. Journal of Applied Meteorology 43, 1308-1328. doi:10.1175/1520-0450(2004)043¡1308:SSFNAN ¿2.0.CO;2.

Chow, F., Weigel, A., Street, R., Rotach, M., Xue, M., 2006. High-resolution large-eddy simulations of flow in a steep alpine valley. part i: Methodology, verification, and sensitivity experiments. Journal of Applied Meteorology and Climatology 45, 63-86. doi:10.1175/JAM2322.1.

Deppe, A.J., Gallus, W.A., Takle, E.S., 2012. A wrf ensemble for improved wind speed forecasts at turbine height. Wea. Forecasting 28, 212-228. URL: http://dx.doi.org/10.1175/WAF-D-11-00112.1, doi:10.1175/WAF-D-11-00112.1.

Dudhia, J., 1995. Reply. Mon. Wea. Rev. 123, 2573-2575. URL: http://dx.doi.org/10.1175/1520-0493(1995)123<2573:R>2.0.C0;2, doi:10.1175/1520-0493(1995)123¡2573:R ¿2.0.CO;2.

Durran, D.R., Klemp, J.B., 1983. A compressible model for the simulation of moist mountain waves. Mon. Wea. Rev. 111, 2341-2361. URL: http://dx.doi.org/10 .1175/1520-0493(1983) 111<2341:ACMFTS>2 . 0 . C0;2, doi:10.1175/1520-0493(1983)111¡2341:ACMFTS¿2.0.CO;2. 
Floors, R., Vincent, C., Gryning, S.E., Pea, A., Batchvarova, E., 2013. The wind profile in the coastal boundary layer: Wind lidar measurements and numerical modelling. Boundary-Layer Meteorology 147, 469-491. URL: http://dx.doi.org/10.1007/s10546-012-9791-9, doi:10.1007/s10546012-9791-9.

Freedman, J., Markus, M., Penc, R., 2008. Analysis of West Texas wind plant ramp-up and ramp-down events. AWSTruewind report .

Grell, G., Emeis, S., Stockwell, W., Schoenemeyer, T., Forkel, R., Michalakes, J., Knoche, R., Seidl, W., 2000. Application of a multiscale, coupled MM5/chemistry model to the complex terrain of the VOTALP valley campaign. Atmospheric Environment 34, 1435-1453.

Grenier, H., Bretherton, C.S., 2001. A moist PBL parameterization for large-scale models and its application to subtropical cloud-topped marine boundary layers. Monthly Weather Review 129, 357-377. URL: http://dx .doi.org/10 .1175/1520-0493(2001)129<0357:AMPPFL>2.0.C0;2, doi:10.1175/1520-0493(2001)129¡0357:AMPPFL¿2.0.CO;2.

Gronas, S., Sandvik, A., 1999. Numerical simulations of local winds over steep orography in the storm over north Norway on October 12, 1996. Journal of Geophysical Research-Atmospheres 104, 9107-9120.

Hanna, S., Yang, R., 2001. Evaluations of mesoscale models' simulations of near-surface winds, temperature gradients, and mixing depths. Journal of Applied Meteorology 40, 1095-1104. doi:10.1175/15200450(2001)040¡1095:EOMMSO ¿2.0.CO;2. 
Harris, L.M., Durran, D.R., 2010. An idealized comparison of one-way and two-way grid nesting. Mon. Wea. Rev. 138, 2174-2187. URL: http://dx.doi.org/10.1175/2010MWR3080.1, doi:10.1175/2010MWR3080.1.

Hong, S.Y., Noh, Y., Dudhia, J., 2006. A new vertical diffusion package with an explicit treatment of entrainment processes. Monthly Weather Review 134, 2318-2341. URL: http://dx.doi.org/10.1175/MWR3199.1, doi:10.1175/MWR3199.1.

Hong, S.Y., Pan, H.L., $1996 . \quad$ Nonlocal boundary layer vertical diffusion in a medium-range forecast model. Monthly Weather Review 124, 2322-2339. URL: http://dx.doi.org/10 .1175/1520-0493(1996) 124<2322: NBLVDI>2 . 0 . CO;2, doi:10.1175/1520-0493(1996)124¡2322:NBLVDI¿2.0.CO;2.

Janjic, Z.I., 1994. The step-mountain eta coordinate model: Further developments of the convection, viscous sublayer, and turbulence closure schemes. Monthly Weather Review 122, 927-945. URL: http: //dx.doi.org/10 .1175/1520-0493(1994) 122<0927 : TSMECM>2 . 0 . C0;2, doi:10.1175/1520-0493(1994)122¡0927:TSMECM¿2.0.CO;2.

Liu, Y., Warner, T., Liu, Y., Vincent, C., Wu, W., Mahoney, B., Swerdlin, S., Parks, K., Boehnert, J., 2011. Simultaneous nested modeling from the synoptic scale to the les scale for wind energy applications. Journal of Wind Engineering and Industrial Aerodynamics 99, 308 - 319. URL: http://www.sciencedirect.com/science/article/pii/S0167610511000158, 
doi:10.1016/j.jweia.2011.01.013. jce:title¿The Fifth International Symposium on Computational Wind Engineeringi/ce:title $i$.

Mahoney, W., Parks, K., Wiener, G., Liu, Y., Myers, W., Sun, J., Delle Monache, L., Hopson, T., Johnson, D., Haupt, S., 2012. A wind power forecasting system to optimize grid integration. Sustainable Energy, IEEE Transactions on 3, 670-682. doi:10.1109/TSTE.2012.2201758.

Marquis, M., Wilczak, J., Ahlstrom, M., Sharp, J., Stern, A., Smith, J., Calvert, S., 2011. Forecasting the wind to reach significant penetration levels of wind energy. Bulletin of the American Meteorological Society 92, 1159-1171. URL: http://dx.doi .org/10.1175/2011BAMS3033.1, doi:10.1175/2011BAMS3033.1.

Mass, C., Albright, M., Ovens, D., Steed, R., MacIver, M., Grimit, E., Eckel, T., Lamb, B., Vaughan, J., Westrick, K., Storck, P., Colman, B., Hill, C., Maykut, N., Gilroy, M., Ferguson, S., Yetter, J., Sierchio, J., Bowman, C., Stender, R., Wilson, R., Brown, W., 2003. Regional environmental prediction over the pacific northwest. Bulletin of the American Meteorological Society 84, 1353-+. doi:10.1175/BAMS-84-10-1353.

Nakanishi, M., Niino, H., 2006. An improved mellor yamada level-3 model: Its numerical stability and application to a regional prediction of advection fog. Boundary-Layer Meteorology 119, 397-407. URL: http://dx.doi.org/10.1007/s10546-005-9030-8, doi:10.1007/s10546005-9030-8.

Park, S., Bretherton, C.S., 2009. The university of washington shallow 
convection and moist turbulence schemes and their impact on climate simulations with the community atmosphere model. Journal of Climate 22, 3449-3469. URL: http://dx.doi.org/10.1175/2008JCLI2557.1, doi:10.1175/2008JCLI2557.1.

Pleim, J.E., 2007. A combined local and nonlocal closure model for the atmospheric boundary layer. part i: Model description and testing. Journal of Applied Meteorology and Climatology 46, 1383-1395. URL: http://dx.doi .org/10.1175/JAM2539.1, doi:10.1175/JAM2539.1.

Skamarock, W., Klemp, J., 2008. A time-split nonhydrostatic atmospheric model for weather research and forecasting applications. Journal of Computational Physics 227, 3465-3485. doi:10.1016/j.jcp.2007.01.037.

Storm, B., Dudhia, J., Basu, S., Swift, A., Giammanco, I., 2009. Evaluation of the Weather Research and Forecasting Model on Forecasting Low-level Jets: Implications for Wind Energy. Wind Energy 12, 81-90. doi:10.1002/we.288.

Sukoriansky, S., Galperin, B., Perov, V., 2005. Application of a new spectral theory of stably stratified turbulence to the atmospheric boundary layer over sea ice. Boundary-Layer Meteorology 117, 231-257. URL: http://dx.doi.org/10.1007/s10546-004-6848-4, doi:10.1007/s10546004-6848-4.

Talbot, C., Bou-Zeid, E., Smith, J., 2012. Nested mesoscale large-eddy simulations with wrf: Performance in real test cases. Journal of Hydrometeorology 13, 1421-1441. 
Wharton, S., Lundquist, J., 2012. Assessing atmospheric stability and its impacts on rotor-disk wind characteristics at an onshore wind farm. Wind Energy 15, 525-546. URL: http://onlinelibrary.wiley.com/doi/10.1002/we.483/abstract, doi:10.1002/we.483.

Williams, J., Maxwell, R., Lundquist, J., Wharton, S., 2009. On the use of a coupled variably-saturated groundwater flow - land surface model to initialize a fully coupled subsurface - land surface - atmospheric model for wind energy forecasting. Eos Trans. AGU Fall Meeting Supplement 90.

Woodward, C., Maxwell, R., Lundquist, J., Mirocha, J., Smith, S., Tompson, A., 2009. Wind Energy Resource Assessment using Coupled GroundwaterLand-Surface Atmospheric Models. Eos Trans. AGU Fall Meeting Supplement 90 .

Wyngaard, J., 2004. Toward numerical modeling in the "terra incognita". Journal of the Atmospheric Sciences 61, 1816-1826.

Xie, B., Fung, J.C.H., Chan, A., Lau, A., 2012. Evaluation of nonlocal and local planetary boundary layer schemes in the wrf model. Journal of Geophysical Research: Atmospheres 117, n/a-n/a. URL: http://dx.doi.org/10.1029/2011JD017080, doi:10.1029/2011JD017080.

Xie, B., Hunt, J.C.R., Carruthers, D.J., Fung, J.C.H., Barlow, J.F., 2013. Structure of the planetary boundary layer over southeast england: Modeling and measurements. Journal of Geophysical Research: Atmospheres 
873 118, 7799-7818. URL: http://dx.doi.org/10.1002/jgrd.50621, $874 \quad$ doi:10.1002/jgrd.50621.

875 Yver, C.E., Graven, H.D., Lucas, D.D., Cameron-Smith, P.J., Keel876 ing, R.F., Weiss, R.F., 2013. Evaluating transport in the wrf model 877 along the california coast. Atmospheric Chemistry and Physics 13, 878 1837-1852. URL: http://www.atmos-chem-phys.net/13/1837/2013/, $879 \quad$ doi:10.5194/acp-13-1837-2013.

Zhang, H., Pu, Z., Zhang, X., 2013. Examination of errors in nearsurface temperature and wind from wrf numerical simulations in regions of complex terrain. Wea. Forecasting 28, 893-914. URL: http://dx.doi.org/10.1175/WAF-D-12-00109.1, doi:10.1175/WAF-D12-00109.1. 


\section{List of Figures}

1 Wind farm topography for the $300 \mathrm{~m}$ horizontal resolution WRF domain comparing (a) the simple terrain site to (b) the complex terrain site. . . . . . . . . . . . . . . . . . . 42

2 West-East cross-section of topography through the center of the $300 \mathrm{~m}$ resolution domain for simulations at different horizontal resolutions (see table 3). . . . . . . . . . . . . . . . 43

3 Horizontal wind speed and direction 48 hour time series for locally-forced simple and complex terrain simulations at different horizontal resolutions at $80 \mathrm{~m}$ hub height compared to SODAR. . . . . . . . . . . . . . . . 44

4 Vertical profiles of horizontal wind speed for locally-forced simple and complex terrain simulations at different horizontal resolutions compared to SODAR at single time slices. . . . . . . 45

5 Horizontal wind speed 48 hour time series for different vertical resolutions for the locally-driven complex and simple terrain cases at $80 \mathrm{~m}$ hub height compared to SODAR. . . . . . . . 46

6 Horizontal wind speed over a 48 hour time series for synopticallyforced simulations over simple and complex terrain (STS and CTS) at different horizontal resolutions compared to SODAR at $80 \mathrm{~m}$ hub height. . . . . . . . . . . . . . 47

7 Horizontal wind speed for saturated and dry soil moisture initializations compared to the base case and SODAR for a 48 hour locally-driven time period over both simple and complex terrain (STL and CTL) at $80 \mathrm{~m}$ above ground. . . . . . . . . . 48

8 Horizontal wind speed 48 hour time series comparing SODAR observations to 1-way (base case) and 2-way nesting for the locally-driven simple and complex terrain sites (STL and CTL) at $80 \mathrm{~m}$ hub height. . . . . . . . . . . . . . . . 49

9 Horizontal wind speed RMSE (m/s) comparing $300 \mathrm{~m}$ horizontal resolution simulation results for different WRF PBL schemes against SODAR observations for each individual case (STL, STS, CTS, CTL) and a time based average for all the cases (Total AVG). PBL schemes are arranged from lowest average RMSE on the left to highest average RMSE on the right. . . . . . . . . . . . . . . 50 
921

10 Horizontal wind speed PDF for locally-forced week-long simulations comparing different horizontal resolutions over simple and complex terrain (STL and CTL) to SODAR at hub height. 51

11 Turbulence intensity PDF for locally-forced week-long simulations comparing different horizontal resolutions over simple and complex terrain (STL and CTL) to SODAR at hub height. 52 


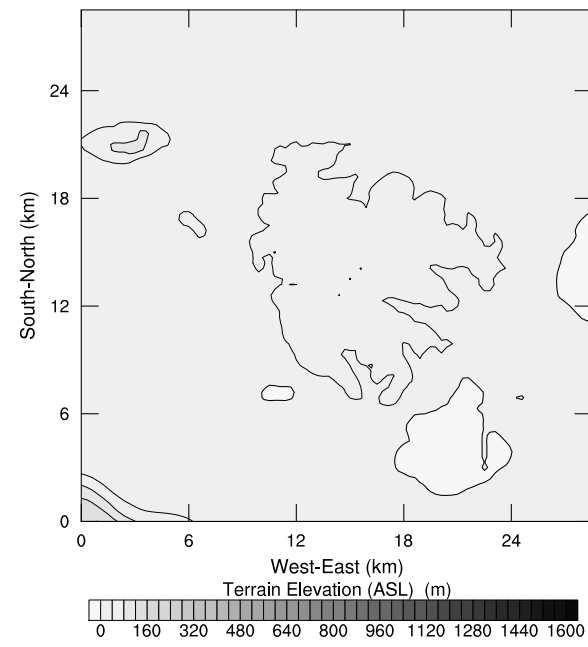

(a)

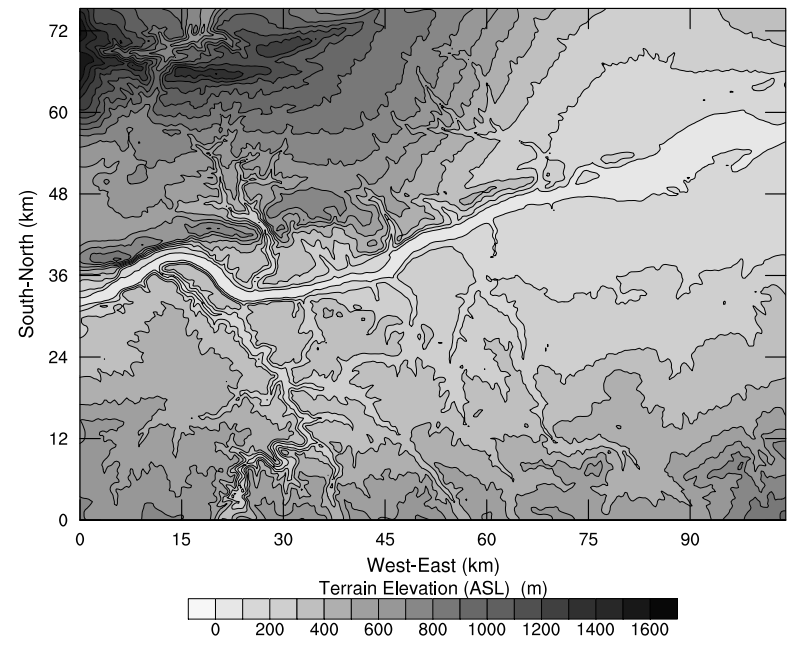

(b)

Figure 1: Wind farm topography for the $300 \mathrm{~m}$ horizontal resolution WRF domain comparing (a) the simple terrain site to (b) the complex terrain site. 


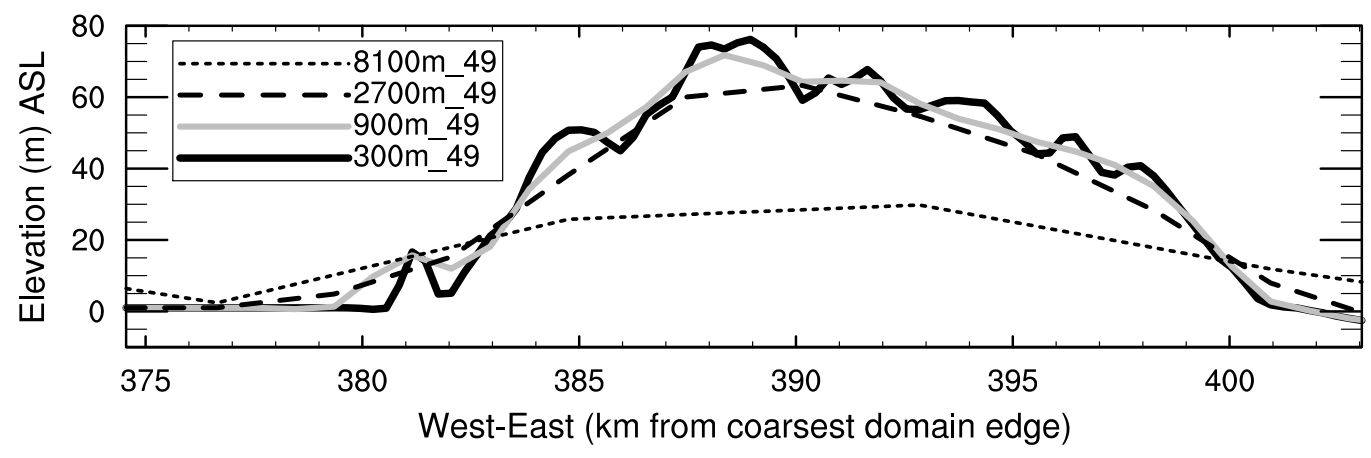

(a) Simple terrain (ST) site

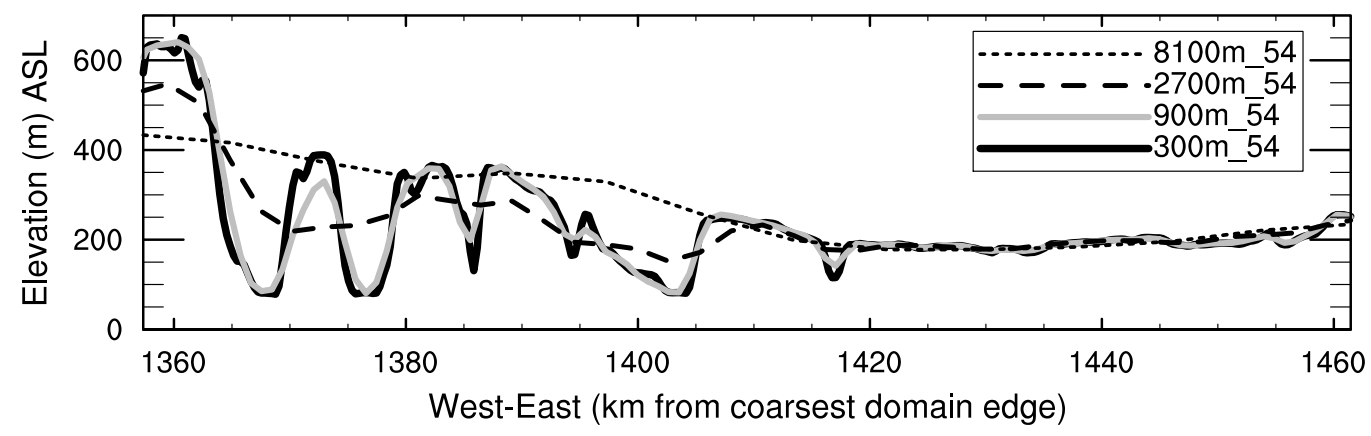

(b) Complex terrain (CT) site

Figure 2: West-East cross-section of topography through the center of the $300 \mathrm{~m}$ resolution domain for simulations at different horizontal resolutions (see table 3). 


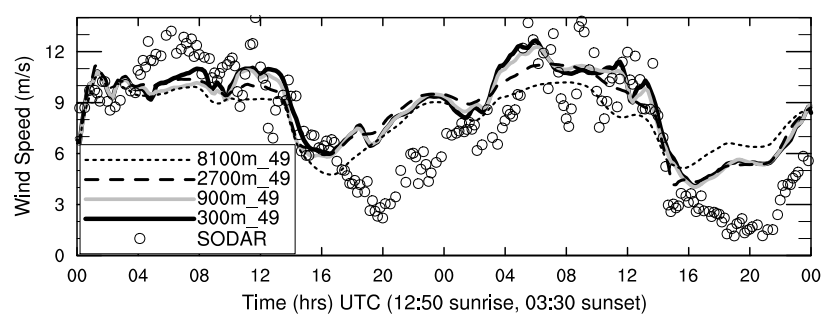

(a) Case STL

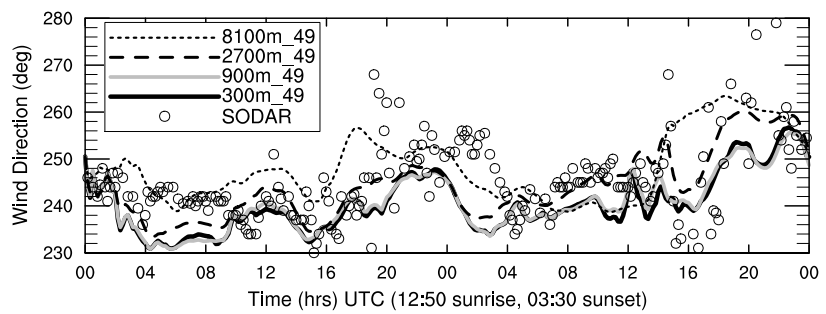

(b) Case STL

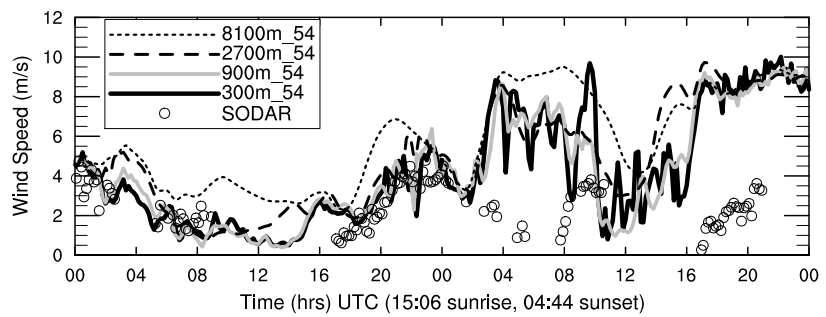

(c) Case CTL

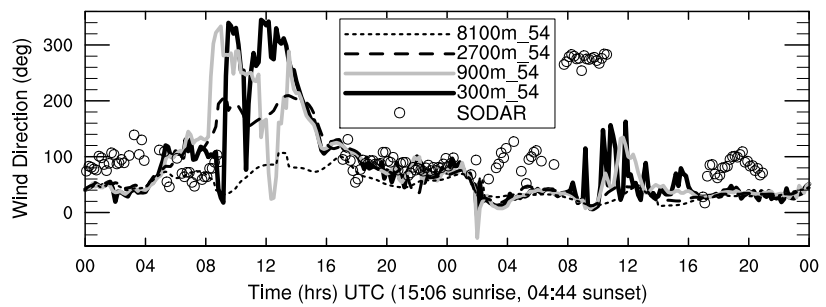

(d) Case CTL

Figure 3: Horizontal wind speed and direction 48 hour time series for locally-forced simple and complex terrain simulations at different horizontal resolutions at $80 \mathrm{~m}$ hub height compared to SODAR. 


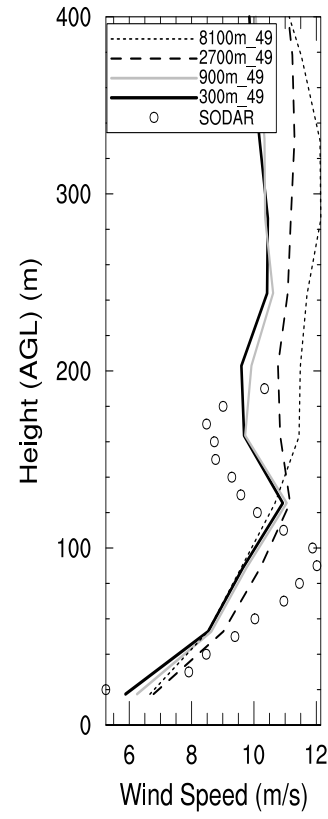

(a) Case STL at 5 UTC on first day.

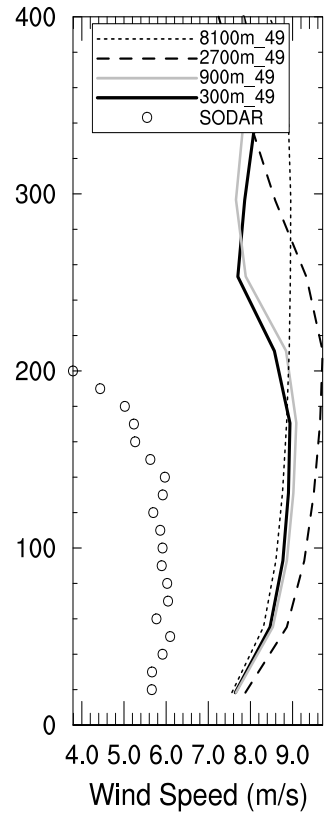

(b) Case STL at 22 UTC on first day.

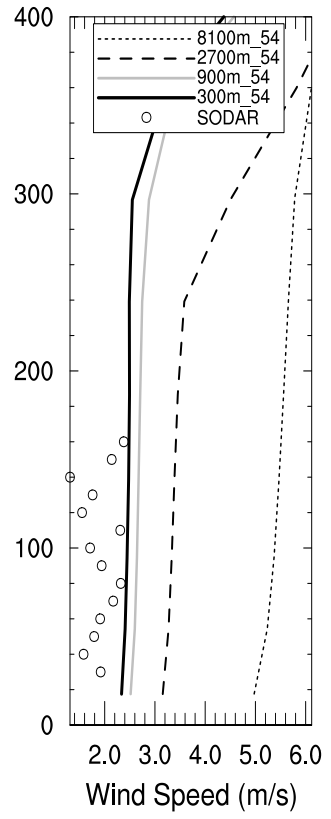

(c) Case CTL at 19.4 UTC on first day.

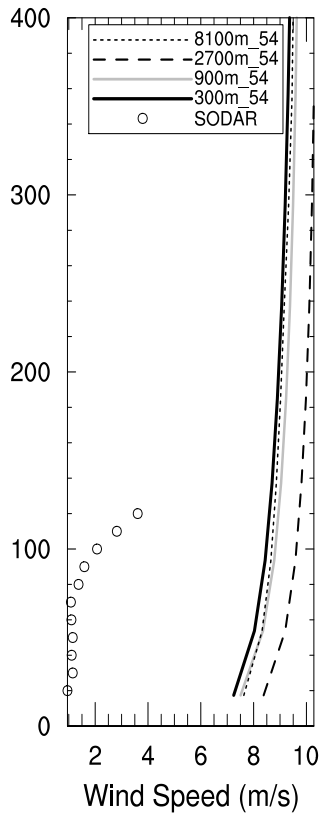

(d) Case CTL at 22 UTC on second day.

Figure 4: Vertical profiles of horizontal wind speed for locally-forced simple and complex terrain simulations at different horizontal resolutions compared to SODAR at single time slices. 


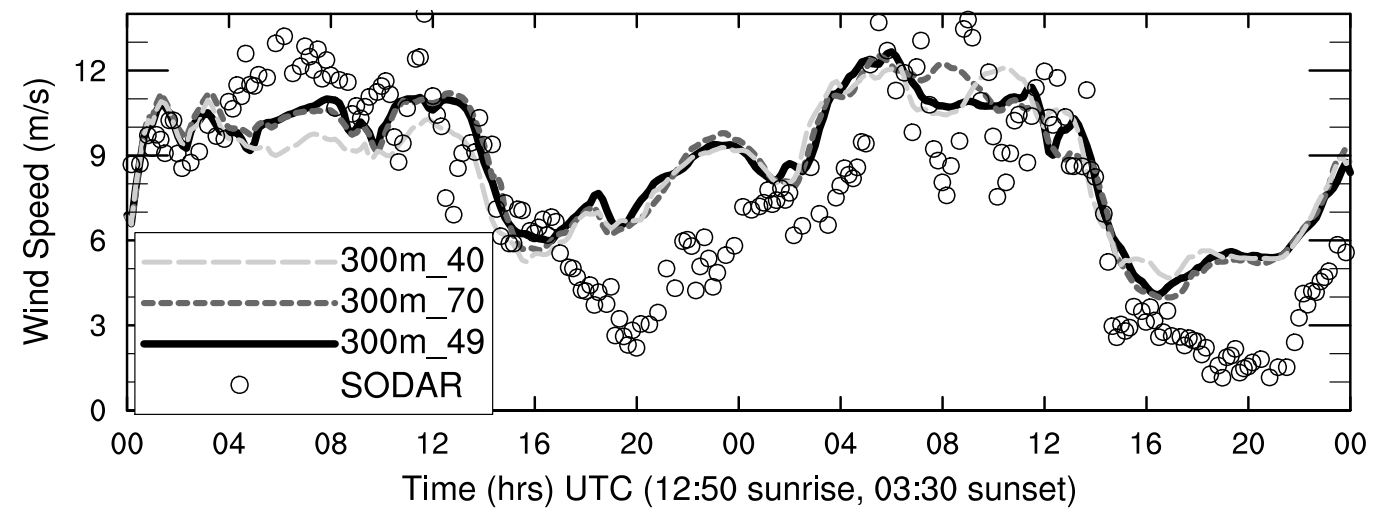

(a) Case STL

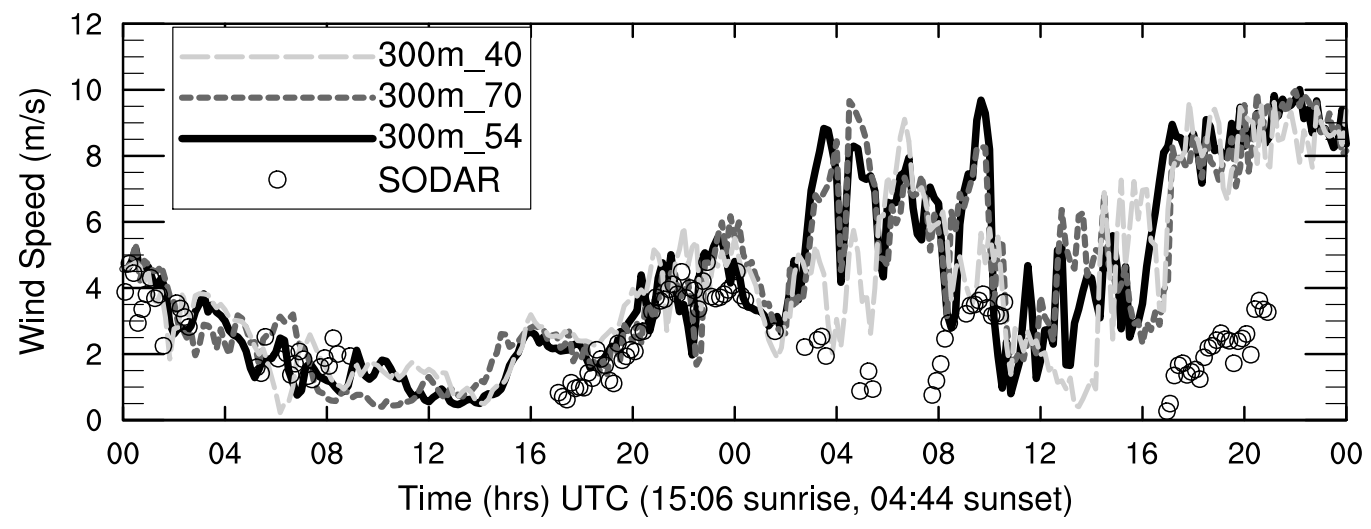

(b) Case CTL

Figure 5: Horizontal wind speed 48 hour time series for different vertical resolutions for the locally-driven complex and simple terrain cases at $80 \mathrm{~m}$ hub height compared to SODAR. 


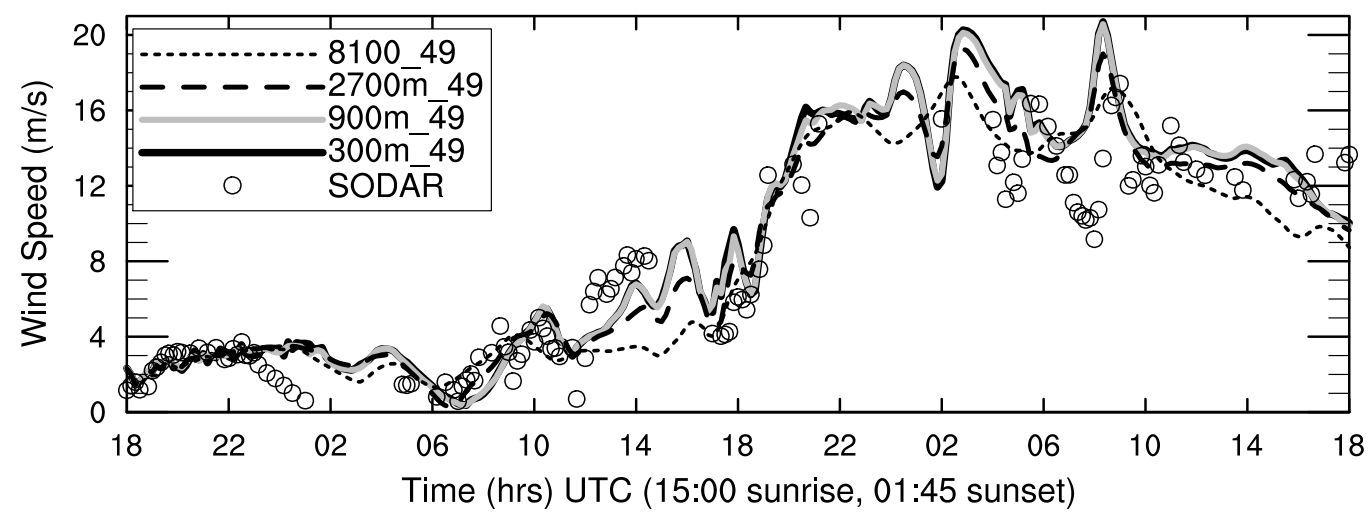

(a) Case STS

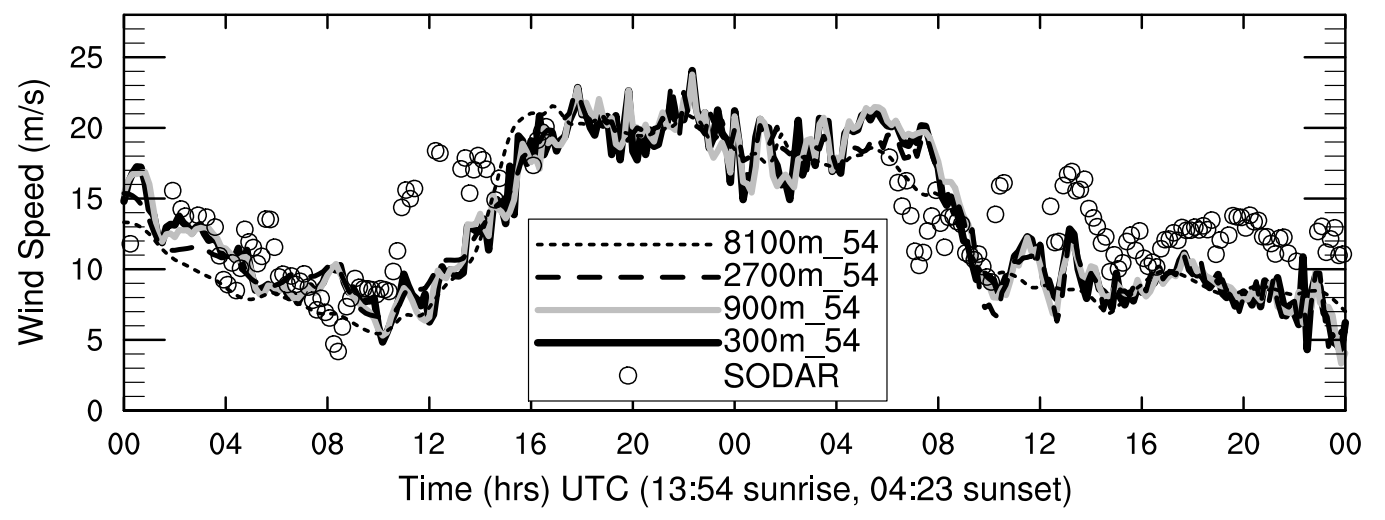

(b) Case CTS

Figure 6: Horizontal wind speed over a 48 hour time series for synoptically-forced simulations over simple and complex terrain (STS and CTS) at different horizontal resolutions compared to SODAR at $80 \mathrm{~m}$ hub height. 


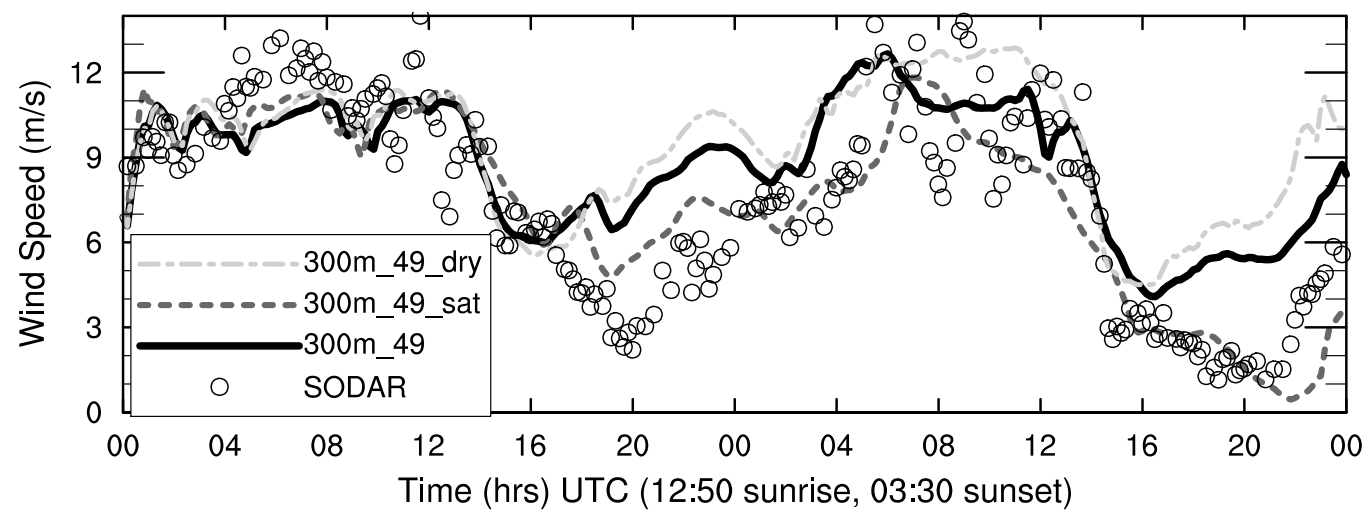

(a) Case STL

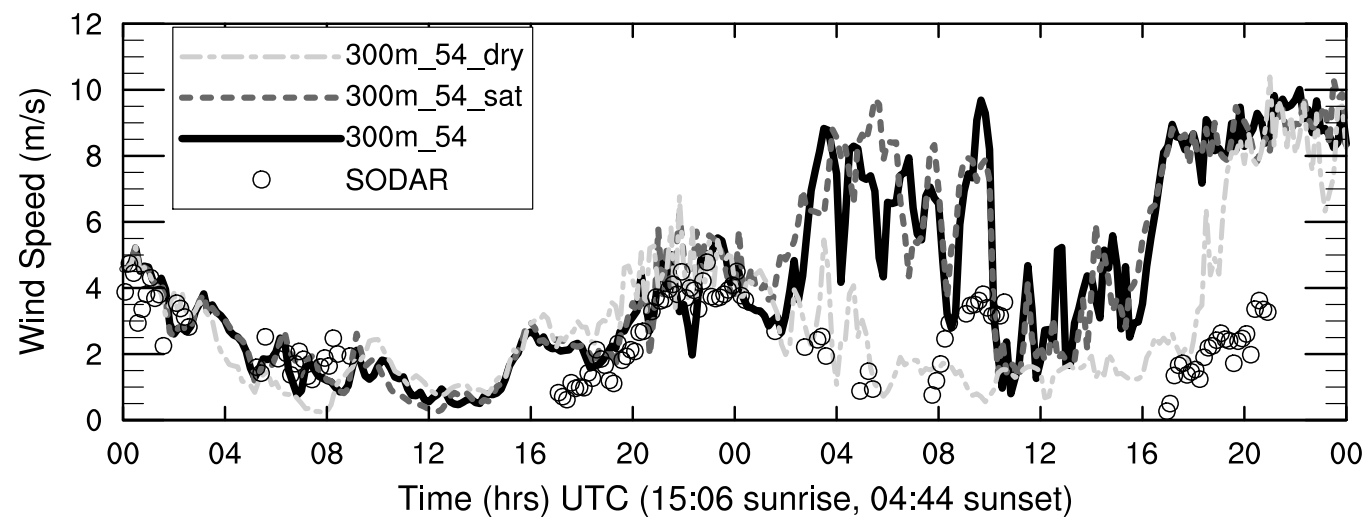

(b) Case CTL

Figure 7: Horizontal wind speed for saturated and dry soil moisture initializations compared to the base case and SODAR for a 48 hour locally-driven time period over both simple and complex terrain (STL and CTL) at $80 \mathrm{~m}$ above ground. 


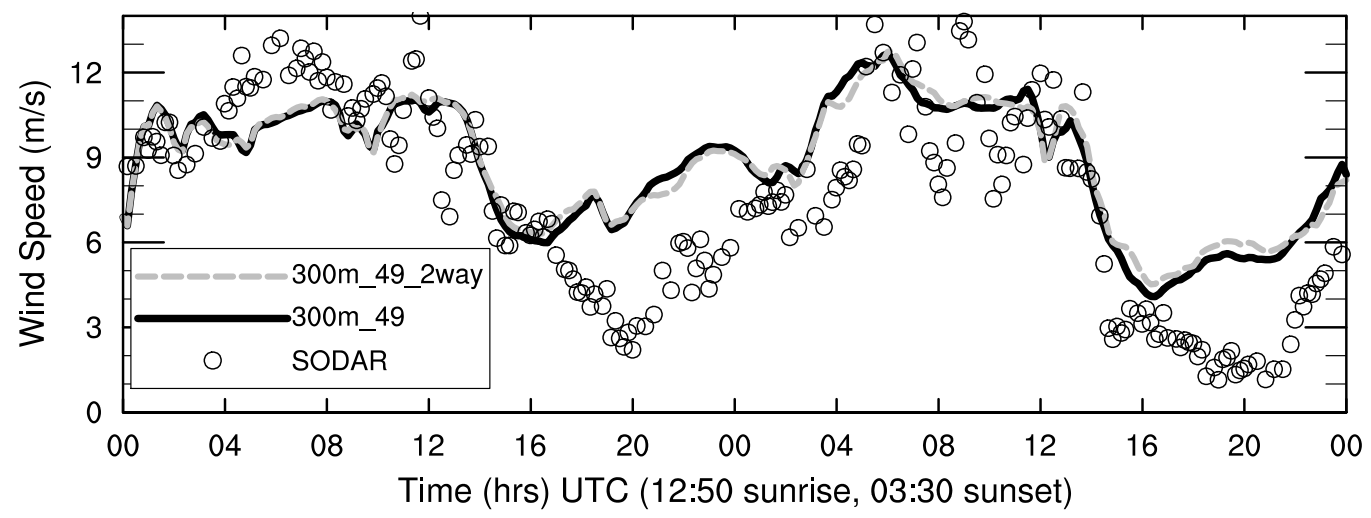

(a) Case STL

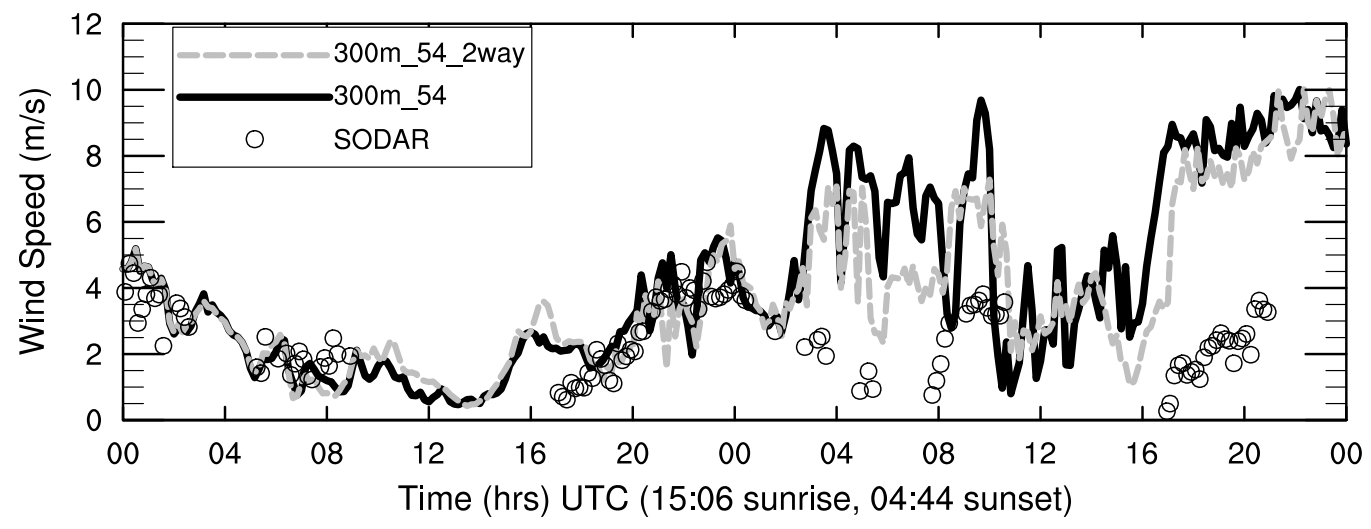

(b) Case CTL

Figure 8: Horizontal wind speed 48 hour time series comparing SODAR observations to 1-way (base case) and 2-way nesting for the locally-driven simple and complex terrain sites (STL and CTL) at $80 \mathrm{~m}$ hub height. 


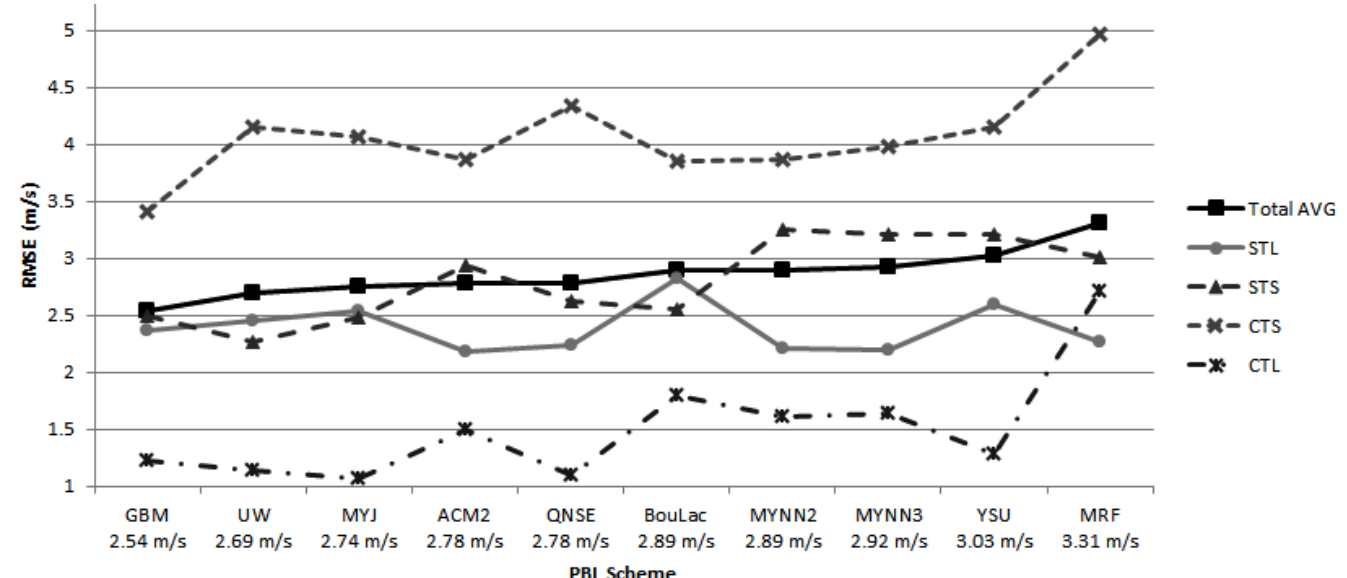

Figure 9: Horizontal wind speed RMSE $(\mathrm{m} / \mathrm{s})$ comparing $300 \mathrm{~m}$ horizontal resolution simulation results for different WRF PBL schemes against SODAR observations for each individual case (STL, STS, CTS, CTL) and a time based average for all the cases (Total AVG). PBL schemes are arranged from lowest average RMSE on the left to highest average RMSE on the right. 


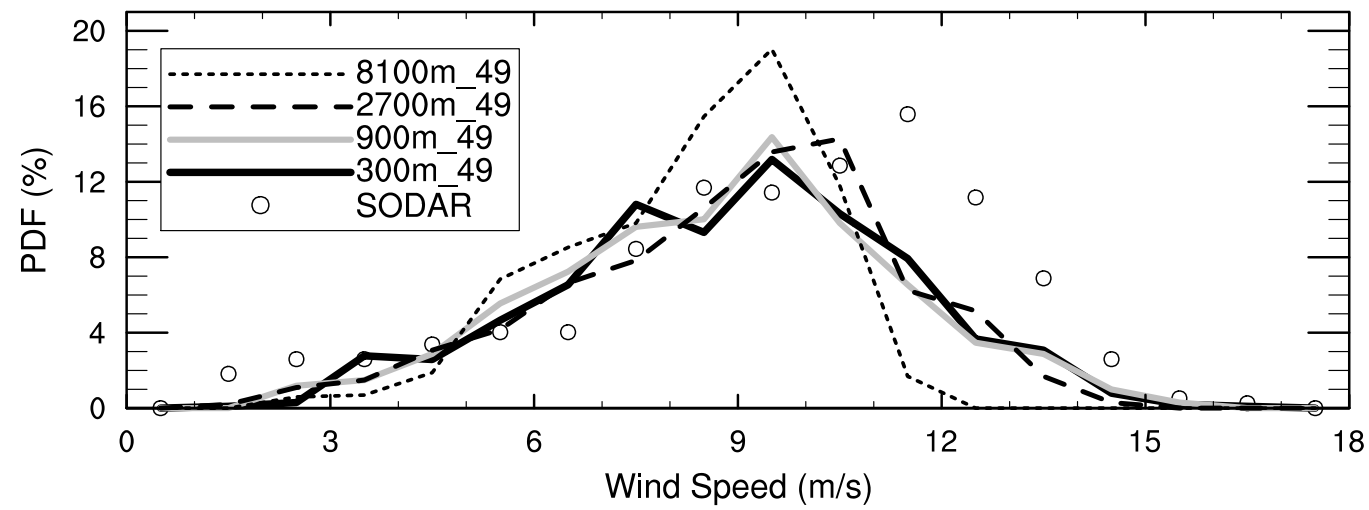

(a) Case STL

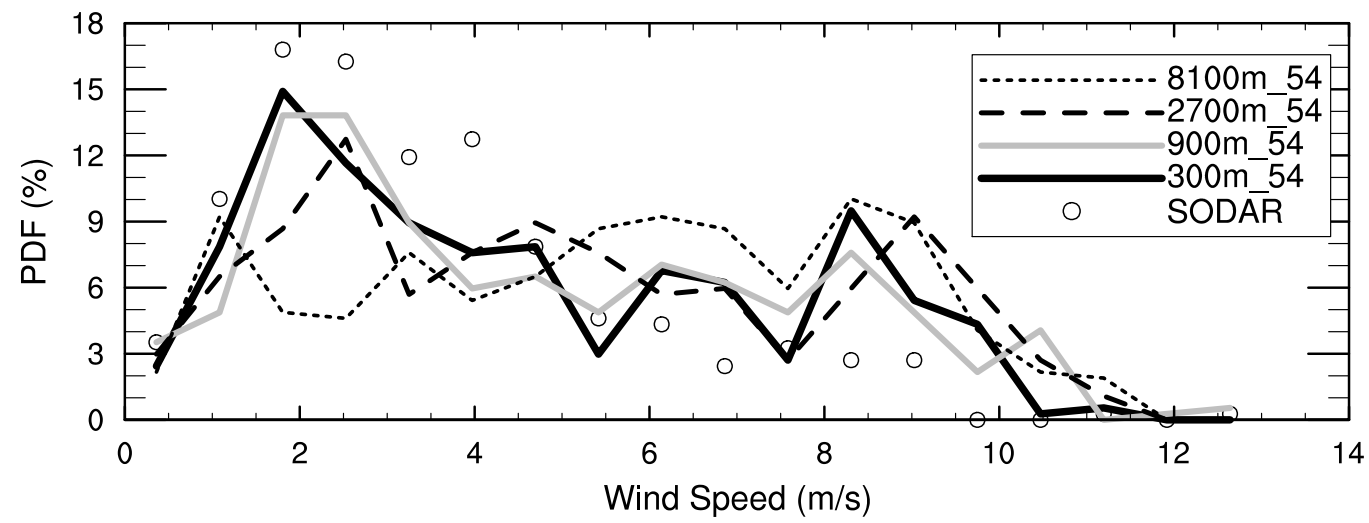

(b) Case CTL

Figure 10: Horizontal wind speed PDF for locally-forced week-long simulations comparing different horizontal resolutions over simple and complex terrain (STL and CTL) to SODAR at hub height. 


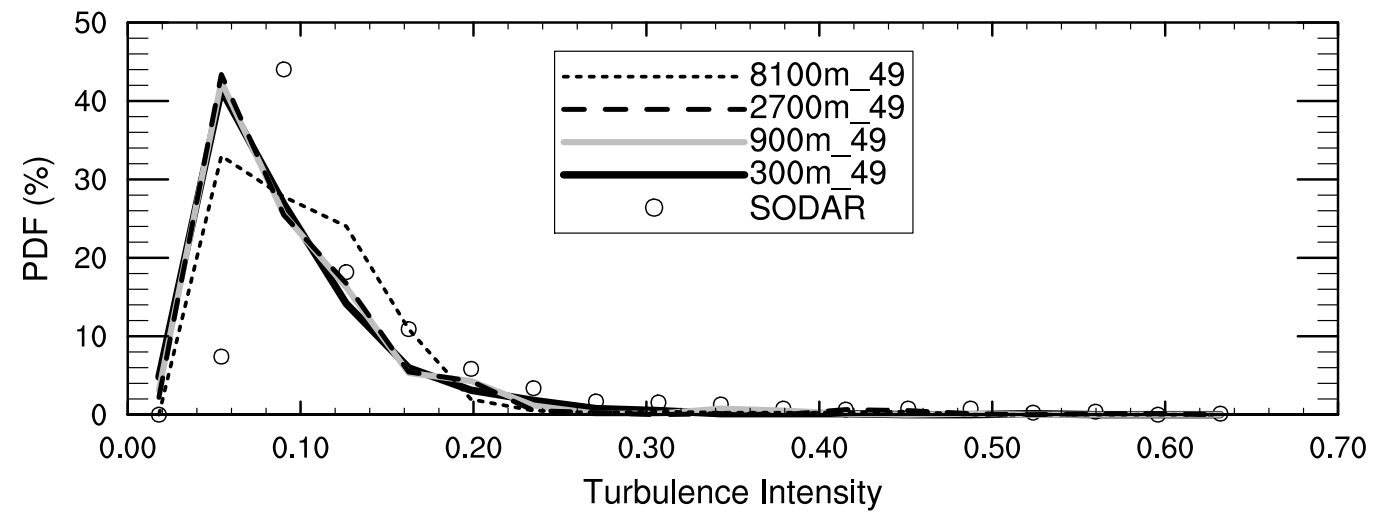

(a) Case STL

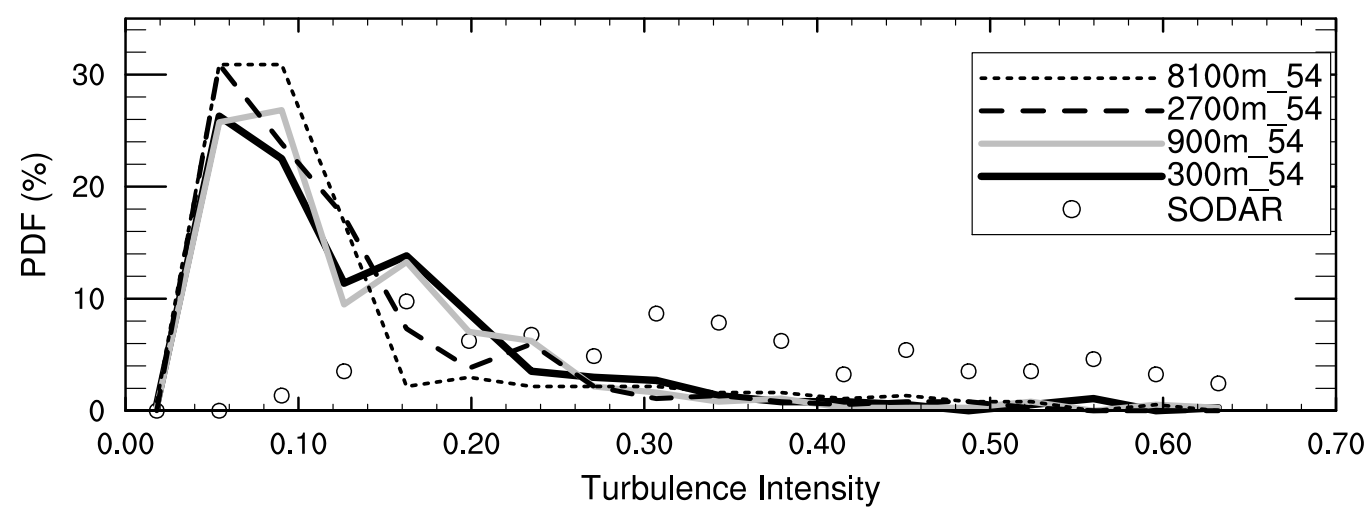

(b) Case CTL

Figure 11: Turbulence intensity PDF for locally-forced week-long simulations comparing different horizontal resolutions over simple and complex terrain (STL and CTL) to SODAR at hub height. 


\section{List of Tables}

1 Simulation parameters for each grid resolution for both the simple and complex terrain sites. . . . . . . . . . . . . . . 54

2 Abbreviations and event descriptions for the different cases investigated. . . . . . . . . . . . . . . 55

3 Simulation configurations and naming (everything is the same as base case unless otherwise noted). . . . . . . . . . . . 56

4 MAE and RMSE (m/s) for horizontal wind speed compared to SODAR over 48 hours for locally-forced simple and complex terrain cases (STL and CTL) at different horizontal resolutions. 57

5 MAE and RMSE $(\mathrm{m} / \mathrm{s})$ of horizontal wind speed for different vertical resolutions of the locally-forced simple and complex terrain cases (STL and CTL) compared to SODAR over 48 hours. . . . . . . . . . . . . . . . . . 58

6 Horizontal wind speed MAE and RMSE (m/s) over a 48 hour period for a synoptically-forced event over simple and complex terrain (STS and CTS) comparing different horizontal resolutions to SODAR. . . . . . . . . . . . . . . 59

7 Horizontal wind speed MAE and RMSE (m/s) for locallydriven simple and complex terrain (STL and CTL) cases comparing different soil moisture initializations to SODAR over a 48 hour period. . . . . . . . . . . . . . . 60

8 MAE and RMSE $(\mathrm{m} / \mathrm{s})$ for wind speed comparing SODAR to 1-way vs. 2-way nesting for the locally-driven simple and complex terrain cases (STL and CTL) over a 48 hour period.

9 Horizontal wind speed MAE and RMSE (m/s) for locallydriven events over simple and complex terrain (STL and CTL) compared to SODAR for a week-long period at hub height. 


\begin{tabular}{|c|c|c|c|c|c|c|c|c|}
\hline & \multicolumn{4}{|c|}{ Simple Terrain } & \multicolumn{5}{c|}{ Complex Terrain } \\
\hline$\triangle h(\mathrm{~m})$ & $(\mathrm{nx}, \mathrm{ny}, \mathrm{nz})$ & $\triangle z_{\min }(\mathrm{m})$ & $\triangle z_{\text {avg }}(\mathrm{m})$ & $\triangle t(\mathrm{~s})$ & $(\mathrm{nx}, \mathrm{ny}, \mathrm{nz})$ & $\triangle z_{\min }(\mathrm{m})$ & $\triangle z_{\text {avg }}(\mathrm{m})$ & $\triangle t(\mathrm{~s})$ \\
\hline 8100 & $(96,96,49)$ & 35 & 246 & 30 & $(348,252,54)$ & 32 & 232 & 30 \\
\hline 2700 & $(96,96,49)$ & 35 & 246 & 10 & $(348,252,54)$ & 32 & 232 & 10 \\
\hline 900 & $(96,96,49)$ & 35 & 246 & 3.33 & $(348,252,54)$ & 32 & 232 & 3.33 \\
\hline 300 & $(96,96,49)$ & 35 & 246 & 1.11 & $(348,252,54)$ & 32 & 232 & 1.11 \\
\hline 300 & $(96,96,40)$ & 60 & 309 & 1.11 & $(348,252,40)$ & 63 & 402 & 1.11 \\
\hline 300 & $(96,96,70)$ & 10 & 177 & 0.74 & $(348,252,70)$ & 12 & 228 & 1.11 \\
\hline
\end{tabular}

Table 1: Simulation parameters for each grid resolution for both the simple and complex terrain sites. 


\begin{tabular}{|c|c|c|c|}
\hline Abbreviation & Description of Event & Actual Ramping Time & Actual Ramping Magnitude \\
\hline STS & $\begin{array}{c}\text { Simple Terrain case, } \\
\text { Synoptically-forced }\end{array}$ & $\begin{array}{c}\text { Frontal passage } 24 \text { hours into } \\
\text { simulation (3 hrs after sunrise) }\end{array}$ & 4 to $16 \mathrm{~m} / \mathrm{s}$ in $3 \mathrm{hrs}$ \\
\hline STL & $\begin{array}{c}\text { Simple Terrain case, } \\
\text { Locally-forced }\end{array}$ & $\begin{array}{c}\text { Appears } 37 \text { hours into } \\
\text { simulation (10 min after sunrise) }\end{array}$ & 10 to $3 \mathrm{~m} / \mathrm{s}$ in 3 hrs \\
\hline CTS & $\begin{array}{c}\text { Complex Terrain case, } \\
\text { Synoptically-forced }\end{array}$ & $\begin{array}{c}\text { Cold front } 10 \text { hours into } \\
\text { simulation (4 hrs before sunrise) }\end{array}$ & 10 to $20 \mathrm{~m} / \mathrm{s}$ in $2 \mathrm{hrs}$ \\
\hline CTL & $\begin{array}{c}\text { Complex Terrain case, } \\
\text { Locally-forced }\end{array}$ & no ramping & no ramping \\
\hline
\end{tabular}

Table 2: Abbreviations and event descriptions for the different cases investigated. 


\begin{tabular}{|c|c|}
\hline Run name & Configuration \\
\hline $300 \mathrm{~m}_{-} 49$ & simple terrain (ST) base case simulation, 4 1-way nested grids, 49 vertical levels, $300 \mathrm{~m}$ horizontal resolution \\
\hline $300 \mathrm{~m}_{-} 54$ & complex terrain $(\mathrm{CT})$ base case simulation, 54 vertical levels \\
\hline $300 \mathrm{~m}_{-} 70$ & 70 vertical levels \\
\hline $300 \mathrm{~m}_{-} 40$ & 40 vertical levels (chosen by WRF) \\
\hline 300m_49_2way, 300m_54_2way & 42 -way nested grids \\
\hline $900 \mathrm{~m} \_49,900 \mathrm{~m} \_54$ & $900 \mathrm{~m}$ horizontal resolution, 3 1-way nested grids \\
\hline $2700 \mathrm{~m} \_49,2700 \mathrm{~m} \_54$ & $2700 \mathrm{~m}$ horizontal resolution, 2 1-way nested grids \\
\hline $8100 \mathrm{~m} \_49,8100 \mathrm{~m} \_54$ & $8100 \mathrm{~m}$ horizontal resolution, 1 grid \\
\hline 300m_49_sat, 300m_54_sat & all grids initialized with saturated soil \\
\hline 300m_49_dry, 300m_54_dry & all grids initialized with dry soil \\
\hline
\end{tabular}

Table 3: Simulation configurations and naming (everything is the same as base case unless otherwise noted). 


\begin{tabular}{|c|c|c|c|c|c|c|}
\hline & \multicolumn{3}{|c|}{ Simple Terrain Case (STL) } & \multicolumn{4}{|c|}{ Complex Terrain Case (CTL) } \\
\hline Resolution & MAE & RMSE & MAE & RMSE & MAE & RMSE \\
\cline { 4 - 7 } & & & & & \multicolumn{2}{|c|}{$1^{\text {st }}$ day } \\
\hline $300 \mathrm{~m}$ & 2.14 & 2.57 & 2.19 & 3.06 & 0.83 & 1.05 \\
\hline $900 \mathrm{~m}$ & 2.16 & 2.57 & 2.10 & 2.93 & 0.95 & 1.19 \\
\hline $2700 \mathrm{~m}$ & 2.17 & 2.62 & 2.31 & 3.17 & 1.12 & 1.43 \\
\hline $8100 \mathrm{~m}$ & 2.27 & 2.74 & 3.24 & 3.88 & 2.04 & 2.28 \\
\hline
\end{tabular}

Table 4: MAE and RMSE $(\mathrm{m} / \mathrm{s})$ for horizontal wind speed compared to SODAR over 48 hours for locally-forced simple and complex terrain cases (STL and CTL) at different horizontal resolutions. 


\begin{tabular}{|c|c|c|c|c|c|c|c|c|}
\hline & \multicolumn{3}{|c|}{ Simple Terrain Case (STL) } & \multicolumn{5}{|c|}{ Complex Terrain Case (CTL) } \\
\hline \multirow[t]{2}{*}{ Resolution } & MAE & RMSE & Avg. Vertical Spacing & MAE & RMSE & MAE & RMSE & \multirow{2}{*}{$\begin{array}{l}\text { Avg. Vertical Spacing } \\
\text { in } 0-200 \mathrm{~m} \text { range }(\mathrm{m})\end{array}$} \\
\hline & & & in $0-200 \mathrm{~m}$ range $(\mathrm{m})$ & & & \multicolumn{2}{|c|}{$1^{\text {st }}$ day } & \\
\hline $300 \mathrm{~m}$ & 2.14 & 2.57 & 38.05 (5 points) & 2.19 & 3.06 & 0.83 & 1.05 & 42.95 (5 points) \\
\hline $300 \mathrm{~m}_{-} 40$ & 2.19 & 2.65 & 73.50 (3 points) & 1.90 & 2.72 & 1.03 & 1.28 & 75.65 (3 points) \\
\hline $300 \mathrm{~m} \_70$ & 2.15 & 2.57 & 9.90 (20 points) & 2.06 & 2.89 & 0.80 & 1.00 & 19.53 (11 points) \\
\hline
\end{tabular}

Table 5: MAE and RMSE (m/s) of horizontal wind speed for different vertical resolutions of the locally-forced simple and complex terrain cases (STL and CTL) compared to SODAR over 48 hours. 


\begin{tabular}{|c|c|c|c|c|}
\hline & \multicolumn{2}{|c|}{ Simple Terrain Case (STS) } & \multicolumn{2}{c|}{ Complex Terrain Case (CTS) } \\
\hline Resolution & MAE & RMSE & MAE & RMSE \\
\hline $300 \mathrm{~m}$ & 1.65 & 2.28 & 3.50 & 4.26 \\
\hline $900 \mathrm{~m}$ & 1.60 & 2.21 & 3.55 & 4.29 \\
\hline $2700 \mathrm{~m}$ & 1.60 & 2.12 & 3.39 & 4.15 \\
\hline $8100 \mathrm{~m}$ & 1.73 & 2.25 & 3.54 & 4.36 \\
\hline
\end{tabular}

Table 6: Horizontal wind speed MAE and RMSE (m/s) over a 48 hour period for a synoptically-forced event over simple and complex terrain (STS and CTS) comparing different horizontal resolutions to SODAR. 


\begin{tabular}{|c|c|c|c|c|}
\hline & \multicolumn{2}{|c|}{ Simple Terrain Case (STL) } & \multicolumn{2}{c|}{ Complex Terrain Case (CTL) } \\
\hline Resolution & MAE & RMSE & MAE & RMSE \\
\hline 300m & 2.14 & 2.57 & 2.19 & 3.06 \\
\hline 300m_sat & 1.54 & 1.95 & 2.22 & 3.10 \\
\hline 300m_dry & 2.67 & 3.27 & 1.37 & 1.87 \\
\hline
\end{tabular}

Table 7: Horizontal wind speed MAE and RMSE (m/s) for locally-driven simple and complex terrain (STL and CTL) cases comparing different soil moisture initializations to SODAR over a 48 hour period. 


\begin{tabular}{|c|c|c|c|c|}
\hline & \multicolumn{2}{|c|}{ Simple Terrain Case (STL) } & \multicolumn{2}{c|}{ Complex Terrain Case (CTL) } \\
\hline Resolution & MAE & RMSE & MAE & RMSE \\
\hline 300m (1-way base case) & 2.14 & 2.57 & 2.19 & 3.06 \\
\hline 300m_2way & 2.17 & 2.60 & 1.71 & 2.38 \\
\hline
\end{tabular}

Table 8: MAE and RMSE (m/s) for wind speed comparing SODAR to 1-way vs. 2-way nesting for the locally-driven simple and complex terrain cases (STL and CTL) over a 48 hour period. 


\begin{tabular}{|c|c|c|c|c|}
\hline & \multicolumn{2}{|c|}{ Simple Terrain Case (STL) } & \multicolumn{2}{c|}{ Complex Terrain Case (CTL) } \\
\hline Resolution & MAE & RMSE & MAE & RMSE \\
\hline $300 \mathrm{~m}$ & 2.24 & 2.74 & 1.85 & 2.64 \\
\hline $900 \mathrm{~m}$ & 2.29 & 2.8 & 1.97 & 2.76 \\
\hline $2700 \mathrm{~m}$ & 2.23 & 2.67 & 2.12 & 2.94 \\
\hline $8100 \mathrm{~m}$ & 2.45 & 2.86 & 2.62 & 3.40 \\
\hline
\end{tabular}

Table 9: Horizontal wind speed MAE and RMSE (m/s) for locally-driven events over simple and complex terrain (STL and CTL) compared to SODAR for a week-long period at hub height. 